\title{
Análisis y correlación de sondeos mecánicos en los depósitos miocenos de Montjuïc (Barcelona): implicaciones estructurales
}

\author{
Analysis and correlation of mechanic boreholes in the Miocene \\ deposits of Montjuïc (Barcelona, Spain): structural implications
}

\begin{abstract}
J.M. Salvany ${ }^{1}$
RESUMEN

Se han estudiado los testigos de un total de 190 sondeos mecánicos que atraviesan los depósitos miocenos de la montaña de Montjuïc, en Barcelona. Son depósitos detríticos en parte bien litificados (arenisca, conglomerado) y en parte inconsolidados (marga, arena, grava), que gradan lateral y verticalmente entre si. En los sondeos realizados en el sector oriental de Montjuïc, estos depósitos forman una serie de $100 \mathrm{~m}$ de espesor, compuesta por 7 ciclos granocrecientes, de origen deltaico-progradante. Por debajo se dispone una unidad masiva aluvial que se extiende hasta un substrato compuesto por rocas metamórficas del Paleozoico, identificado en el subsuelo del puerto de Barcelona. Los sondeos realizados en el sector occidental cortan una serie de hasta $80 \mathrm{~m}$ de espesor compuesta por 4 ciclos detríticos granodecrecientes, de origen aluvial-retrogradante que culminan con depósitos marinos. Esta serie se dispone discordante sobre un substrato de sedimentos continentales del Mioceno Inferior (Burdigaliense), identificado en el subsuelo del extremo oriental de la montaña. La serie deltaica del sector oriental corresponde a una posición estratigráfica por encima de la aluvial del otro sector. Se interpreta que ambos sectores están desplazados por una falla lístrica, de dirección NE-SO, que habría causado el hundimiento del sector oriental y a la vez su basculamiento hacia el NO. Esta falla, a la que se ha denominado falla de Miramar, formaría parte del sistema de fallas extesionales con la misma dirección que han configurado el margen litoral catalán a lo largo del Neógeno. Los depósitos miocenos de ambos sectores están también deformados por un suave anticlinal, de dirección NO-SE, que se reconoce bien tanto en superficie como en subsuelo. Este anticlinal tendría un origen sin-sedimentario, anterior a la falla de Miramar. Se interpreta que sería el resultado de una compactación diferencial entre los sedimentos aluviales y deltaicos precozmente cementados que forman el núcleo del pliegue, y los inconsolidados que forman los flancos. Todas estas estructuras han quedado posteriormente fosilizadas por los depósitos cuaternarios que cubre la montaña de Montjuïc.
\end{abstract}

Palabras clave: Litoestratigrafía, Mioceno, sondeos, Montjuïc, geología urbana

\section{ABSTRACT}

Cores from 190 mechanic boreholes that cut through the Miocene deposits of Montjuïc mountain (Barcelona) were studied. Part of these deposits are well lithified (sandstone, conglomerate) while other parts are not (marl, sand and gravel). There is a significant lateral and vertical gradation between the lithified and non-lithified parts. In the eastern sector of Montjuïc, these deposits form a $100 \mathrm{~m}$ thick sequence made up of 7 coarsening-upward cycles of progradant deltaic origin. Below these cycles there is a massive alluvial unit that extends downward until it reaches a Paleozoic basement made up of metamorphic rocks identified in the subsoil of the Barcelona harbour. In the western sector of Montjuïc, the boreholes cut through a $80 \mathrm{~m}$ thick sequence made up of 4 fining-upward cycles of retrogradant alluvial origin with minor marine deposits at the top. This sequence is developed over the

\footnotetext{
${ }^{1}$ Dept. Enginyeria del Terreny, Cartogràfica i Geofísica, Universitat Politècnica de Catalunya, Campus Nord, D2, c/ Jordi Girona 31, 08034 Barcelona, Email: josepm.salvany@upc.edu
} 
continental deposits of the Early Miocene (Burdigalian) found in the subsoil of the western edge of Montjuï. The deltaic sequence of the eastern sector corresponds to a higher stratigraphic position than the alluvial sequence of the western sector. Both sectors are bounded by a listric fault of NE-SO strike, which may have caused the sinking of the eastern sector and its tilting toward the NW. This fault would be related to the extensional fault system that formed the coastal Catalan margin during the Neogene period. The entire Miocene unit of Montjuïc was also folded and form a gentle anticline of NO-SE strike. This fold would have originated before the faulting and can be interpreted as a synsedimentary structure originated by a differential compaction between the early cemented alluvial and deltaic sediments that form the fold core and the unconsolidated sediments that form its limbs. Both the anticline and the fault were subsequently unconformably covered by the Quaternary deposits that cover the mountain of Montjuïc.

Keywords: Lithostratigraphy, Miocene, boreholes, Montjuïc, urban geology

\section{Introducción}

Montjuïc es una montaña costera que se eleva entre el llano de Barcelona y los deltas del Llobregat y del Besòs (Fig. 1). Esta montaña está compuesta por depósitos detríticos miocenos y, en menor medida, por una cobertera cuaternaria relativamente continua que cubre tanto la parte alta de la montaña como sus diferentes vertientes. Desde finales del siglo XIX, los depósitos miocenos han sido objeto de numerosos estudios geológicos, principalmente de estratigrafía, paleontología y petrología sedimentaria. Son de destacar los de Carez (1881), Almera (1899), Faura y Sans (1908, 1917), San Miguel de la Cámara (1912), Colom \& Bauzá (1945), Gimeno \& Padreny (1947), Thomas Doménech $(1953,1954)$, Suñer Coma (1956), San Miguel Arribas \& Masriera (1970), Magné (1978), Villalta (1964), Villalta \& Rosell (1965), Parcerisa (2002), Parcerisas et al. (2001, 2008) y Gómez-Gras et al. (2000, 2001), todos ellos basados únicamente en el análisis de los afloramientos existentes.

Desde el año 2001 hasta la actualidad, en Montjuïc se han perforado numerosos sondeos mecánicos relacionados con diferentes proyectos constructivos de la ciudad de Barcelona. Son sondeos que alcanzan profundidades de hasta $70 \mathrm{~m}$ y cortan desde los niveles más altos de la montaña hasta su substrato, ofreciendo en conjunto una relevante información geológica de subsuelo hasta ahora inédita. El presente estudio tiene por objeto describir las columnas litológicas de estos sondeos, hacer su correlación estratigráfica, e integrar esta información con la geología de superficie. Se pretende con ello mejorar el nivel de conocimiento litoestratigráfico y estructural hasta ahora existente del conjunto de Montjuïc.

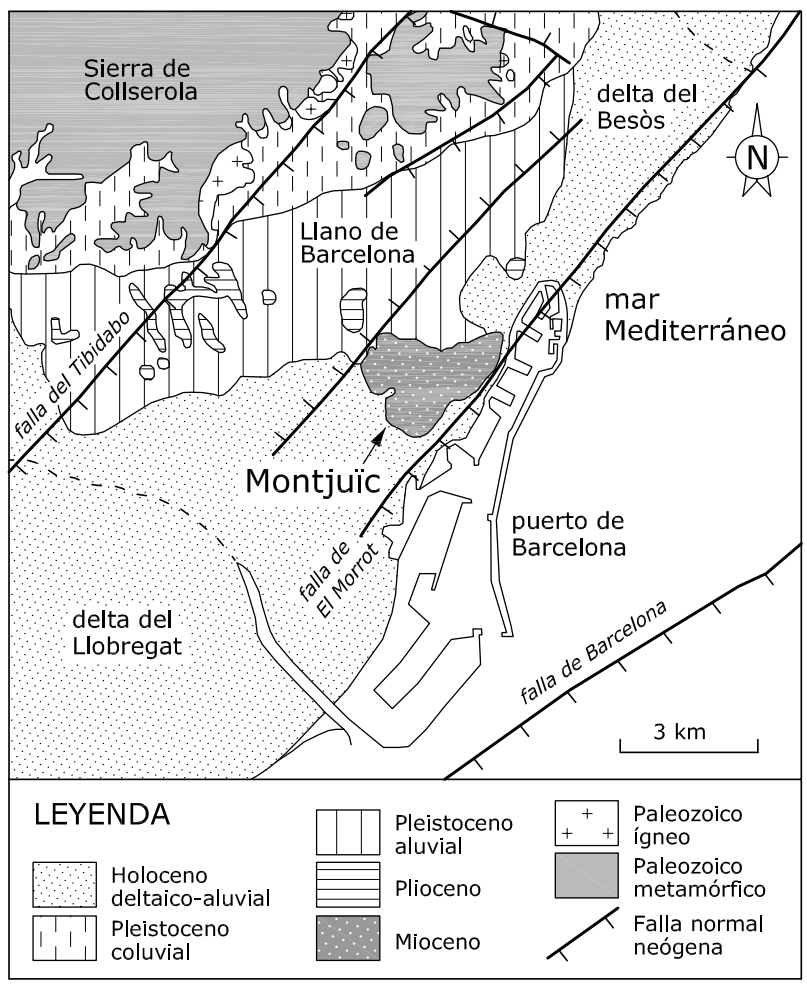

Fig. 1.-Mapa geológico del entorno de Montjuïc, adaptado del ICC (2005). La falla de Barcelona procede del estudio de Bartrina et al. (1992). Las otras fallas proceden del estudio de Llopis Lladó (1942a).

\section{Marco geológico}

Los materiales que forman Montjuïc se originaron durante el Mioceno medio (Serravaliense según Parcerisa, 2002) como sedimentos aluviales y deltaicos depositados sobre un substrato de rocas mesozoicas y del Mioceno Inferior (Parcerisa et al., 2008). Parte de estos sedimentos litificaron precozmente y dieron lugar a capas de arenisca y conglo- 


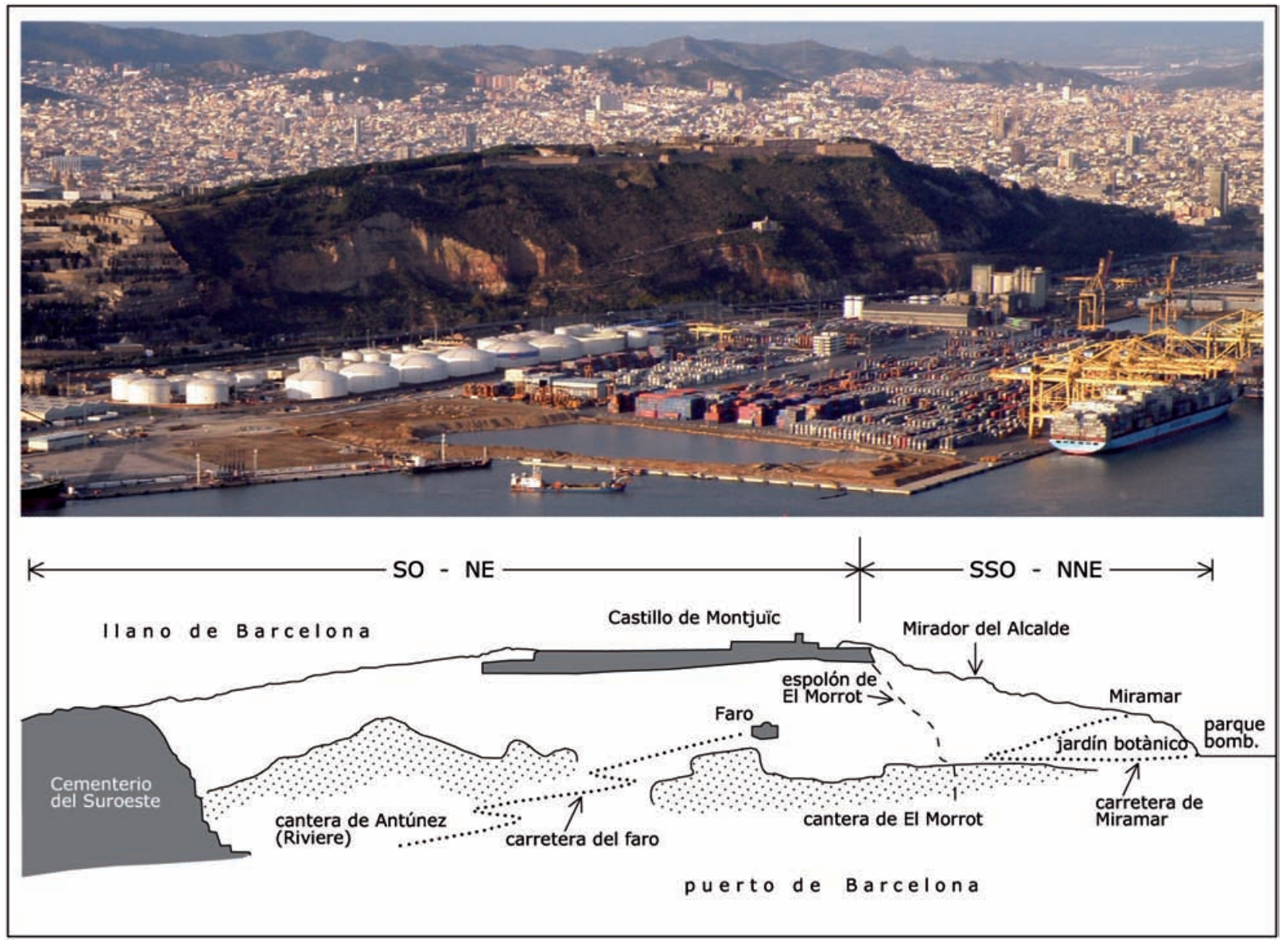

Fig. 2.-Vista aérea del acantilado que forma el margen oriental de Montjuïc.

merado que lateral y verticalmente enlazan con niveles inconsolidados de marga, arena y grava (Gómez-Gras et al., 1999, 2001).

La sedimentación tuvo lugar en un contexto tectónico extensional, activo desde el Oligoceno superior (Bartrina et al., 1992), que produjo el hundimiento del margen litoral principalmente a través de las fallas de dirección NE-SO del Tibidabo y de Barcelona (Fig. 1). Con posterioridad a la sedimentación, y aun en régimen extensional, los materiales de Montjuïc fueron afectados por fallas menores que generaron bloques con hundimiento diferencial. Según Llopis Lladó (1942b), la montaña de Montjuiic sería un bloque elevado (horst) entre dos de estas fallas menores, concretamente la falla de El Morrot, en el margen oriental de la montaña, y otra falla similar en su margen occidental (Fig. 1).

El Mioceno Superior representa una etapa de erosión de la zona litoral catalana ligada a la caída del nivel del mar Maditerráneo ocurrida durante este periodo (crisis messiniense), en la que se reciclan parte de los sedimentos de Montjuïc. La superficie erosiva generada queda posteriormente cubierta por los sedimentos pliocenos marinos, que se disponen discordantes sobre los miocenos (Vicente, 1986). A finales del Plioceno tiene lugar un nuevo periodo erosivo que quedará a su vez cubierto por los sedimentos continentales pleistocenos que constituyen el llano de Barcelona (Llopis Lladó, 1942a; Solé Sabarís, 1963, Riba \& Colombo, 2009). La formación de los deltas cuaternarios recientes del Llobregat y del Besòs constituye un último ciclo sedimentario, desarrollado sobre los depósitos cuaternarios antiguos y los pliocenos, hasta dar lugar a la configuración geológica actual (Marqués, 1984; Gàmez, 2007; Velasco et al., 2012).

Desde un punto de vista geomorfológico, la montaña de Montjuïc constituye dos diferentes sectores: 


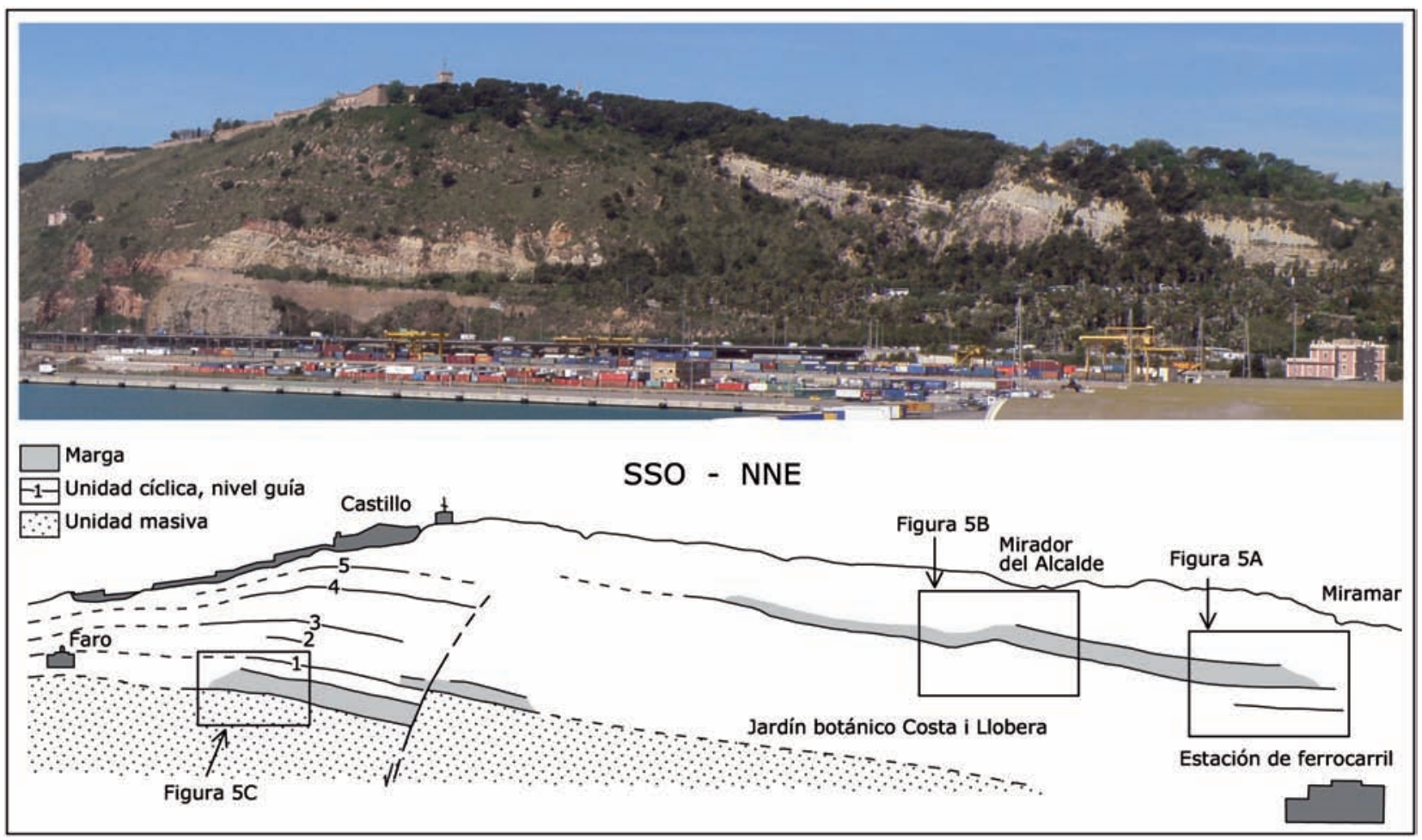

Fig. 3.-Panoràmica de la zona Morrot-Miramar del acantilado del margen oriental de Montjuïc, con indicación de las principales unidades estratigráficas que afloran.

un sector oriental, que forma el relieve más elevado y abrupto de la montaña, que se eleva hasta $175 \mathrm{~m}$ de altura; y un sector occidental, de menor altura y con suaves vertientes hacia el NE y el SO. El límite entre ambos sectores no es preciso, pero viene marcado por un súbito cambio de pendiente alrededor de la cota de los $100 \mathrm{~m}$.

Las principales capas de arenisca que forman ambos sectores han sido objeto de numerosas explotaciones a cielo abierto, que han sido activas desde los inicios de la construcción de la ciudad de Barcelona (canteras romanas) hasta finales de los años 60 del pasado siglo en que fueron definitivamente clausuradas (Roca i Blanch, 2000). En ellas se explotaba la "piedra de Montjuïc", muy valorada principalmente como material para la construcción de edificios. Una parte de estas canteras han sido cubiertas y han desaparecido. Otras han sido rehabilitadas como parques o zonas deportivas. En este segundo caso persisten aún parte de los antiguos frentes de explotación. En estos frentes se pueden observar las capas de arenisca de la parte superior de la montaña, así como la cobertera cuaternaria que en algunos casos llegan a superar los $10 \mathrm{~m}$ de espesor. Es una cobertera coluvial que se compone principalmente de arcillas rojas que engloban gravas y bloques de arenisca, y contienen abundantes nódulos edáficos de carbonato.

\section{Sondeos estudiados}

En el sector oriental de Montjuïc se han estudiado un total de 48 sondeos mecánicos: 4 corresponden al proyecto de construcción del túnel de Miramar (Geotec-262, 2001); 11 al proyecto de construcción de un nuevo parque de bomberos próximo al puerto de Barcelona (Bosch \& Ventayol, 2008); 13 al proyecto de auscultación y estabilización de movimientos de ladera de la montaña en el jardín botánico Costa i Llobera (Beuter Blasco, 2007a; 2007b); 4 al proyecto de estabilización del escarpe del mirador del Alcalde (Bosch \& Ventayol, 2007); 14 al proyecto de remodelación del castillo de Montjuïc (CCG, 2009; G3, 2012); y 2 al proyecto de construcción de un puente en el puerto de Barcelona, (Geopayma, 2010). A excepción de este último proyecto, que fue encargado por la Autoritad Portuaria de Barcelona (Ministe- 


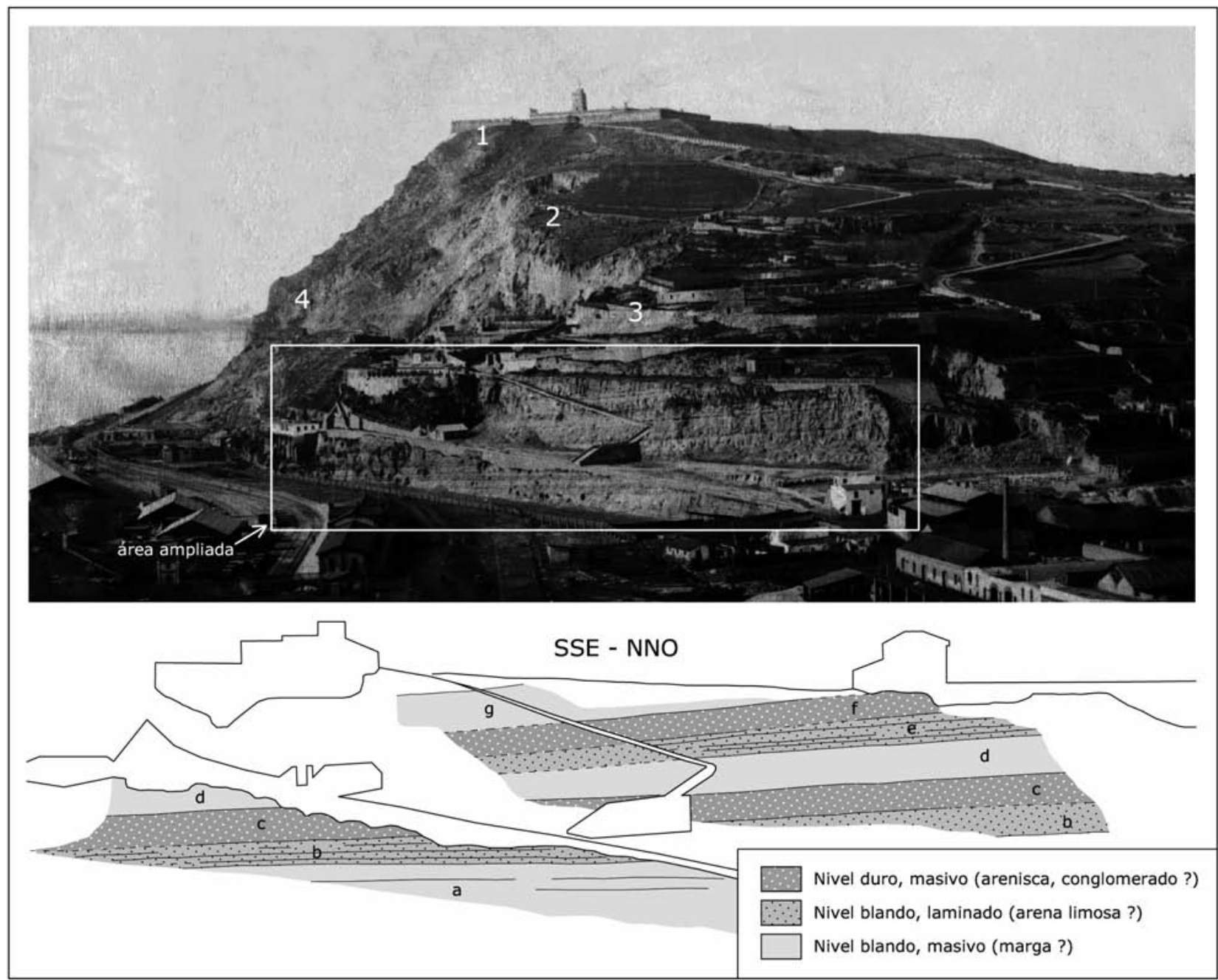

Fig. 4.-Fotointerpretación del afloramiento actualmente desaparecido del extremo norte de Montjuïc (zona de Miramar), a partir de una fotografía del año 1905. El afloramiento muestra el flanco septentrional del sinclinal de Miramar, compuesto por los niveles inferiores de la unidad cíclica (foto cedida por el Arxiu Fotogràfic de Barcelona). 1 castillo de Montjuïc, 2 mirador del Alcalde, 3 zona del actual túnel de Miramar, 4 perfil de El Morrot.

rio de Fomento), los demás corresponden a proyectos promovidos por el Ayuntamiento de Barcelona.

En el sector occidental se han estudiado un total de 78 sondeos correspondientes al proyecto de ampliación de la Línea 2 del Metro de Barcelona, que atraviesa el subsuelo de Montjuïc desde el llano de Barcelona hasta el delta del Llobregat (GISA, 2007). Estos sondeos se realizaron en dos diferentes campañas: una durante el año 2003 (anteproyecto), con 13 sondeos, todos ellos perforados en Montjuïc; y otra durante el año 2007, con 65 sondeos, 35 de ellos perforados en Montjuïc i los demás en los llanos periféricos de Barcelona y del delta del Llobregat. También se han estudiado cerca de 100 sondeos correspondientes a la construcción de la Línea 10 del Metro de Barcelona, en el tramo que discurre por el subsuelo del paseo de la Zona Franca (GISA, 2002). Ambas líneas de Metro corresponden a proyectos promovidos por la Generalitat de Catalunya.

Todos estos sondeos se han realizado con recuperación de testigo continuo, y con un buen grado de recuperación. La información de los sondeos del túnel de Miramar, parque de bomberos, puerto de Barcelona y una parte de los de la Línea 10, procede de los informes geotécnicos de las empresas que los realizaron. En los demás casos, la información procede del análisis de los testigos de los sondeos realizada directamente por el autor con criterio sedimentológico. 

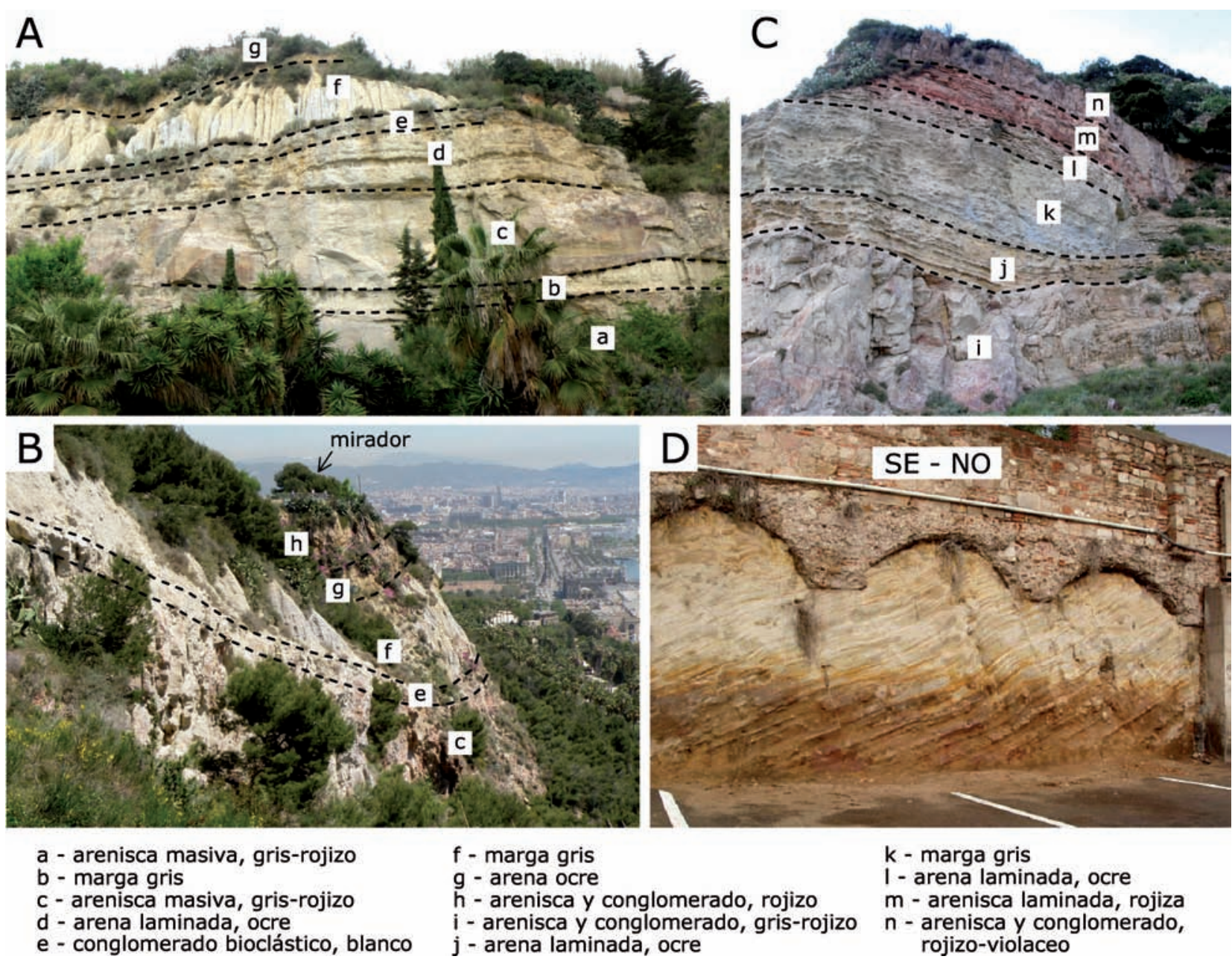

Fig. 5.-Afloramientos representativos de la zona Morrot-Miramar: (A) Miramar; (B) mirador del Alcalde; (C) parte inferior del espolón de El Morrot. Las capas i y j representan el techo de la unidad masiva, las otras representan el primer ciclo de la unidad cíclica; D) parque de bomberos de Montjuïc (foto cedida por Bosch \& Ventayol). Ver figura 3 para la situación de A, B y C. Ver figura 6 para la situación de D.

\section{Sector oriental}

\section{Geología de superficie}

El margen oriental de Montjuïc forma un continuo acantilado de cerca de $2 \mathrm{~km}$ de longitud que constituye la principal zona de afloramientos de la montaña (Fig. 2). Este acantilado no es rectilíneo. Tiene una parte meridional de dirección NE-SO, de aproximadamente $1,5 \mathrm{~km}$ de longitud, y una parte septentrional de dirección NNE-SSO, de $450 \mathrm{~m}$ de longitud. La zona donde se produce el cambio de dirección forma un suave espolón rocoso conocido desde antiguo con la denominación de El Morrot. Las capas miocenas que afloran entre El Morrot y el cementerio construido en el extremo sur de la montaña muestran una estructura prácticamente horizontal. Por el contrario, desde El Morrot hacia el norte (Miramar) las capas están inclinadas hacia el NNE con un buzamiento de hasta 10 grados, que se suaviza gradualmente en este mismo sentido (Fig. 3). En el extremo norte de acantilado las capas invierten su buzamiento formando una suave estructura sinclinal, conocida desde antiguo como el sinclinal de Vista Alegre (Carez, 1881) o de Miramar (Almera, 1899). Antiguamente, este sinclinal afloraba (Fig. 4), pero ha sido progresivamente cubierto por la urbanización de la montaña. En la actualidad aún aflora una pequeña parte de su flanco norte en el patio del parque de bomberos de Montjuïc (Fig. 5D). 


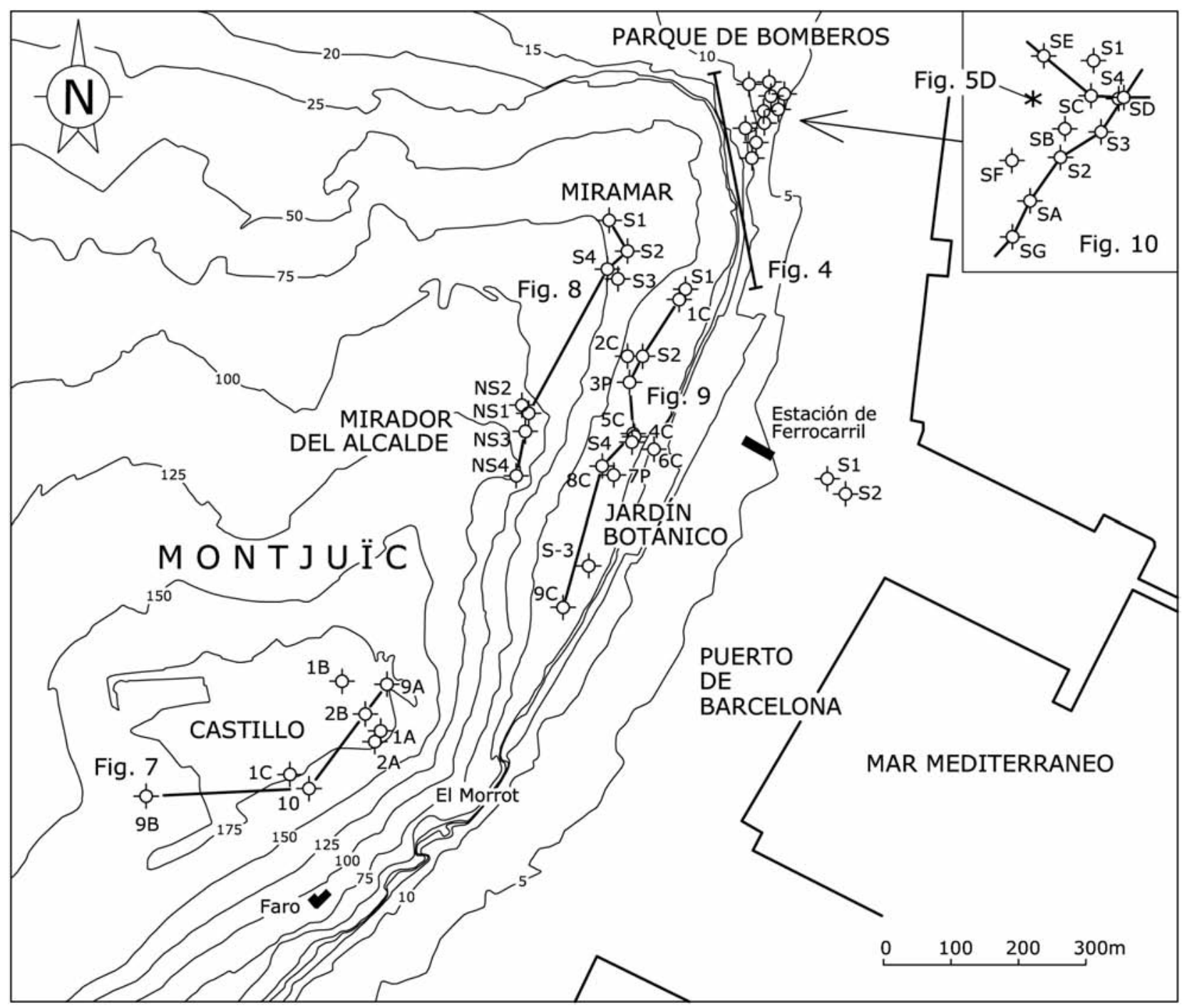

Fig. 6.-Mapa del sector oriental de Montjuïc con la localización de los sondeos estudiados y de los cortes representados en las figuras $7,8,9$ y 10 .

El cementerio fue inaugurado en 1883 , y ha ido creciendo progresivamente hasta alcanzar una superficie actual de 57 hectáreas. Constituye una amplia zona de la montaña totalmente cubierta en la que, a excepción de la cantera Moragas dentro del cementerio, no se puede hacer ningún tipo de observación geológica. Antes de su construcción, esta parte de Montjuïc mostraba una estructura de capas con buzamiento hacia el SO, que se sumergían bajo los sedimentos cuaternarios del delta del Llobregat (Almera, 1899).

En su conjunto, el acantilado de Montjuïc representa una suave estructura anticlinal, descrita ya por Carez (1881) y Almera (1899). El tramo entre el faro i el cementerio, donde las capas se observan prácticamente horizontales, representa una ancha zona de charnela. La zona entre el faro y Miramar, y la zona del cementerio, que buzan en sentido opuesto, constituyen los dos flancos del pliegue. El eje de este anticlinal sería aproximadamente perpendicular a la línea de costa.

Desde un punto de vista estratigráfico, el acantilado oriental de Montjuïc permiten reconocer dos principales unidades litológicas miocenas (Fig. 3): una unidad inferior masiva, formada principalmente por capas de arenisca y conglomerado, y una unidad superior con alternancia cíclica de capas de marga, arena, arenisca y conglomerado. La primera unidad 


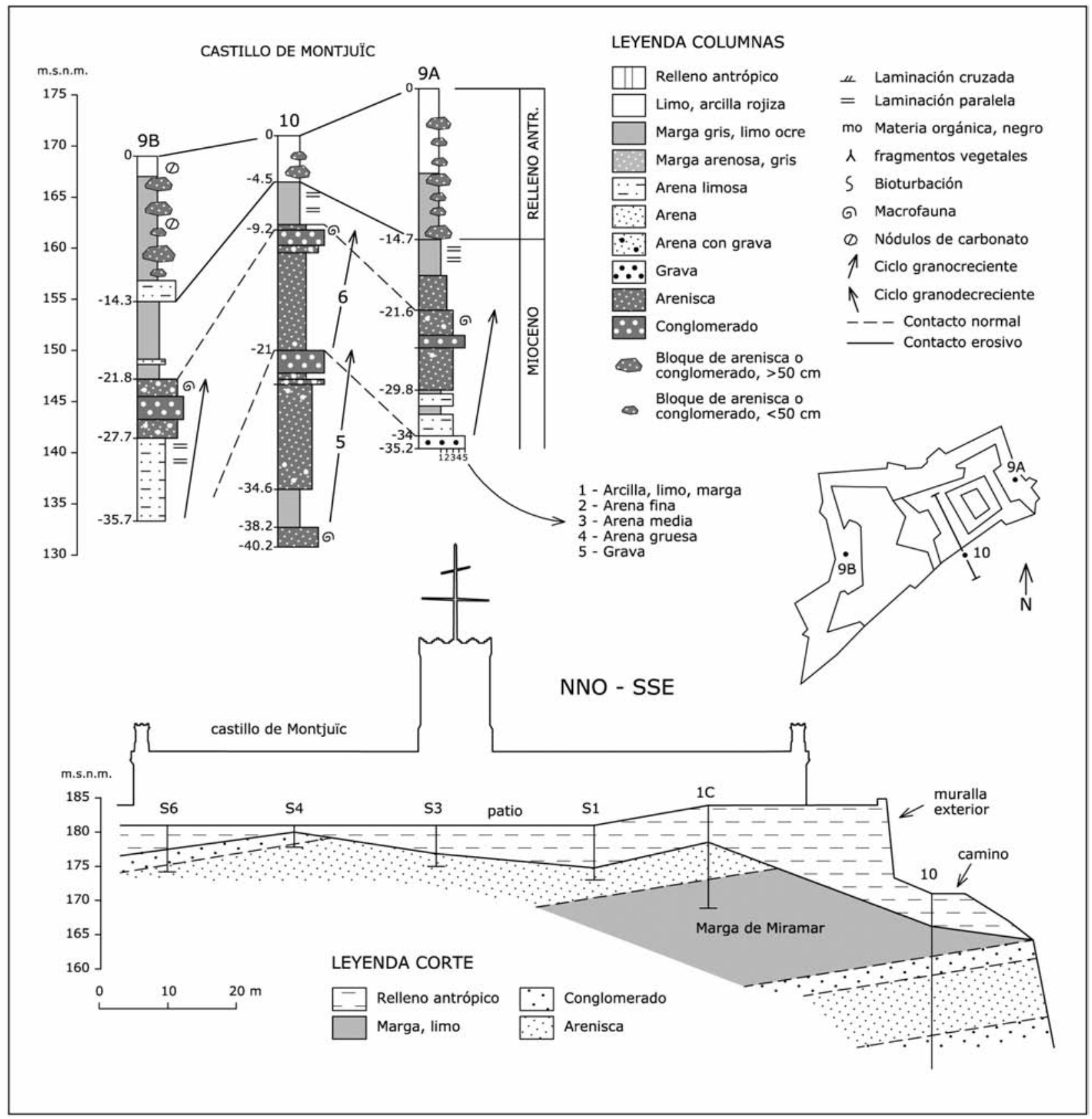

Fig. 7.-Correlación de sondeos del castillo de Montjuïc. Los sondeos 9A, 9B y 10 corresponden a la campaña del 2009 ; los S1 al S6, corresponden a la campaña del 2012. Ver la figura 6 para la situación de los sondeos.

forma un continuo escarpe en la base del acantilado, sobre el que se han excavado las principales canteras de este sector. Se corresponde con la Unidad Morrot de Gómez-Gras et al. (2001). La unidad cíclica se extiende por la parte alta del acantilado y está en buena parte cubierta por derrubios de vertiente. Se corresponde con las unidades Castell, Miramar y Mirador de estos mismos autores.
En la zona de Miramar afloran los niveles altos de la serie miocena. Se reconoce un tramo basal de arenisca rojiza masiva, de $12 \mathrm{~m}$ de espesor, que intercala un capa menor de marga gris de $1 \mathrm{~m}$ de espesor (niveles a, b y c de la Fig. 5A); un tramo intermedio de arena fina y limo, ocre, con un nivel de conglomerado bioclástico a techo, con un espesor de $5 \mathrm{~m}$ (niveles d y e); y un tramo superior margoso gris de 


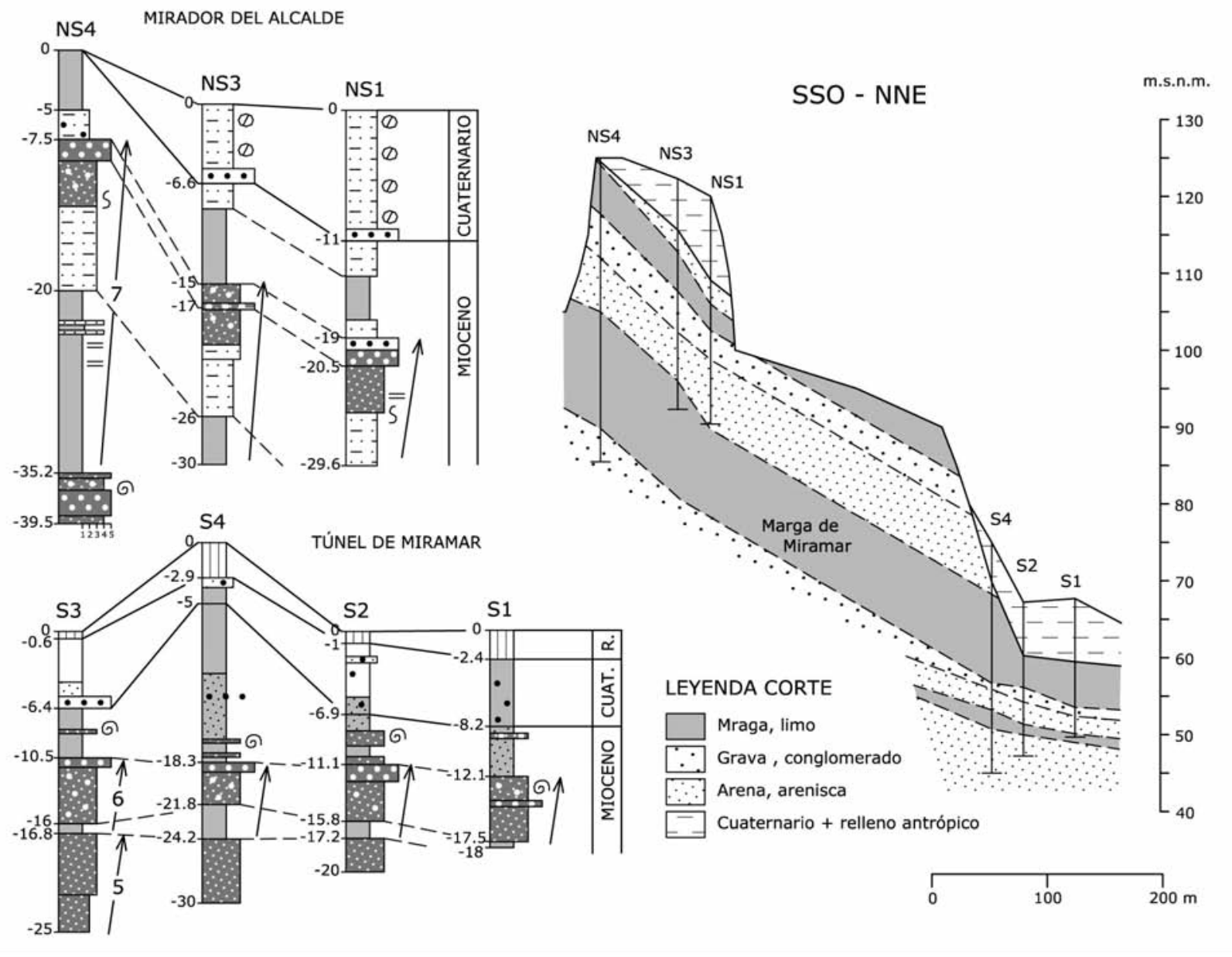

Fig. 8.-Correlación de sondeos del mirador del Alcalde y del túnel de Miramar. Las columnas del túnel de Miramar están adaptadas del estudio de Geotec-262 (2001). Ver la figura 7 para la leyenda de las columnas y la figura 6 para la situación de los sondeos.

$15 \mathrm{~m}$ de espesor (nivel f). Los tramos basal e intermedio equivalen a la parte superior de la Unidad Castell antes referida. El tramo superior equivale a la Unidad Miramar. En el mirador del Alcalde, por encima del tramo superior margoso aflora un cuarto tramo compuesto por capas de arena ocre y arenisca, con un espesor del orden de $20 \mathrm{~m}$ (niveles $\mathrm{g}$ y h de la Fig. 5B), que equivale a la Unidad Mirador.

El espolón de El Morrot ofrece un perfil estratigráfico más completo. Afloran $70 \mathrm{~m}$ de espesor de la unidad masiva, sin llegarse a ver su base que se extiende en subsuelo hasta una profundidad desconocida. Por encima, y hasta la cumbre de la montaña, se extiende la unidad cíclica. En ella se identifican 5 ciclos con espesores de entre 15 y $20 \mathrm{~m}$ cada uno de ellos (Fig. 3). Los $20 \mathrm{~m}$ superiores están cubiertos por derrubios. Al pie de la muralla del castillo afloran unos pocos metros de arenisca y conglomerado que representan el techo de la serie, a la cota de $175 \mathrm{~m}$. Cada ciclo se compone de un tramo basal margoso o margo-arenoso grisáceos (niveles k, 1 de la Fig. 5C); un tramo intermedio de arena y/o arenisca de grano medio ocre o rojizo, con estructura laminada (nivel $\mathrm{m}$ ); y un tramo superior masivo de arenisca y conglomerado rojizo-violáceo (nivel n). El contraste de durezas entre este tramo superior masivo y los niveles basales de marga del siguiente ciclo forma un escalón rocoso que se puede seguir relativamente bien en el relieve del acantilado. Por el contrario, el tramo basal margoso tiende a formar un relieve más suave y a estar cubierto de vegetación (aflora puntualmente).

El carácter cíclico de esta unidad fue inicialmente descrito por San Miguel de la Cámara (1912). 


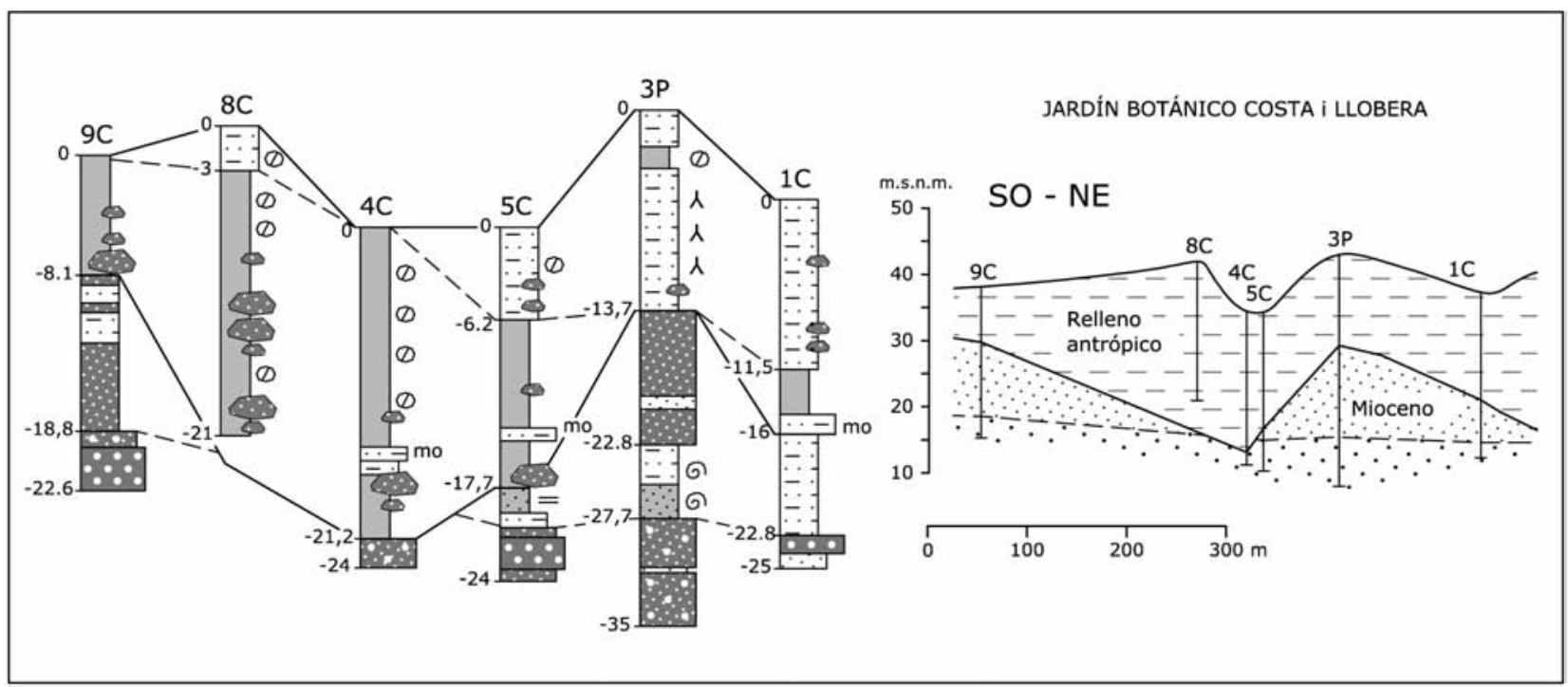

Fig. 9.-Correlación de sondeos del jardín botánico Costa i Llobera. Ver la figura 7 para la leyenda de las columnas y la figura 6 para la situación de los sondeos.

Villalta \& Rosell (1965) identifican los 5 ciclos y hacen una descripción litoestratigráfica detallada de los mismos. Gómez-Gras et al. (2001) hacen el estudio sedimentológico de esta unidad que interpretan como el resultado de la evolución de un sistema deltaico progradante.

\section{Sondeos del castillo de Montjuïc}

Los sondeos del castillo de Montjuïc corresponden a dos diferentes campañas. En la primera campaña (CCG, 2009) se realizaron tres sondeos profundos alrededor del castillo, de hasta $40 \mathrm{~m}$ de longitud (Figs. 6 y 7), y otros cinco más cortos, de hasta $15 \mathrm{~m}$ de longitud, en el interior del mismo. En la segunda campaña $(G 3,2012)$ se realizaron seis sondeos cortos en uno de los patios interiores del castillo, de hasta $8 \mathrm{~m}$ de longitud.

Los sondeos largos de la primera campaña cortan la parte superior de la unidad cíclica, justamente la que en superficie está cubierta por derrubios. En el sondeo 10 se identifican dos ciclos granocrecientes de similares características a los observados en el perfil de El Morrot (Fig. 7). El ciclo inferior, de 17,2 m de espesor, muestra una sucesión completa con un nivel basal de marga gris, un nivel intermedio de arenisca, y un nivel superior de conglomerado. El segundo ciclo, de 11,8 m de espesor, muestra una sucesión similar, aunque en él no está desarrollado el nivel basal de marga. Por encima se registra un tramo margoso de $6,4 \mathrm{~m}$ de espesor que se reconoce también en la parte superior de los otros dos sondeos largos. Por encima de este tramo superior margoso, los tres sondeos cortan una serie caótica de bloques de arenisca englobados en limo ocre o arcilla roja, de hasta $14,7 \mathrm{~m}$ de espesor en el sondeo 9A, que se ha interpretado como un relleno antrópico, probablemente depositado con el fin de nivelar la parte alta de la montaña durante la construcción del castillo.

Los sondeos cortos del interior del castillo cortan niveles de arenisca y conglomerado situados estratigraficamente por encima del tramo margoso de la parte superior del sondeo 10. En conjunto constituyen un tercer ciclo granocreciente, que habría formado la cumbre de la montaña antes de la construcción del castillo. Estos niveles superiores de arenisca y conglomerado son los que afloran en la base de la muralla del castillo, entre los sondeos 10 y $9 \mathrm{~A}$.

El techo del primer ciclo del sondeo 10 se sitúa a la cota de 150 m (Fig. 7). Esta cota es similar a la que se encuentra el techo del quinto ciclo que aflora en el perfil de El Morrot (Fig. 3). La equivalencia entre ambos niveles es razonable dada su proximidad. El tramo superior cubierto del acantilado correspondería, por tanto, a los dos ciclos superiores de los sondeos. Integrando la información de superficie con la de los sondeos, la unidad cíclica estaría en su conjunto compuesta por 7 ciclos, con un espesor total aproximado de $100 \mathrm{~m}$. 

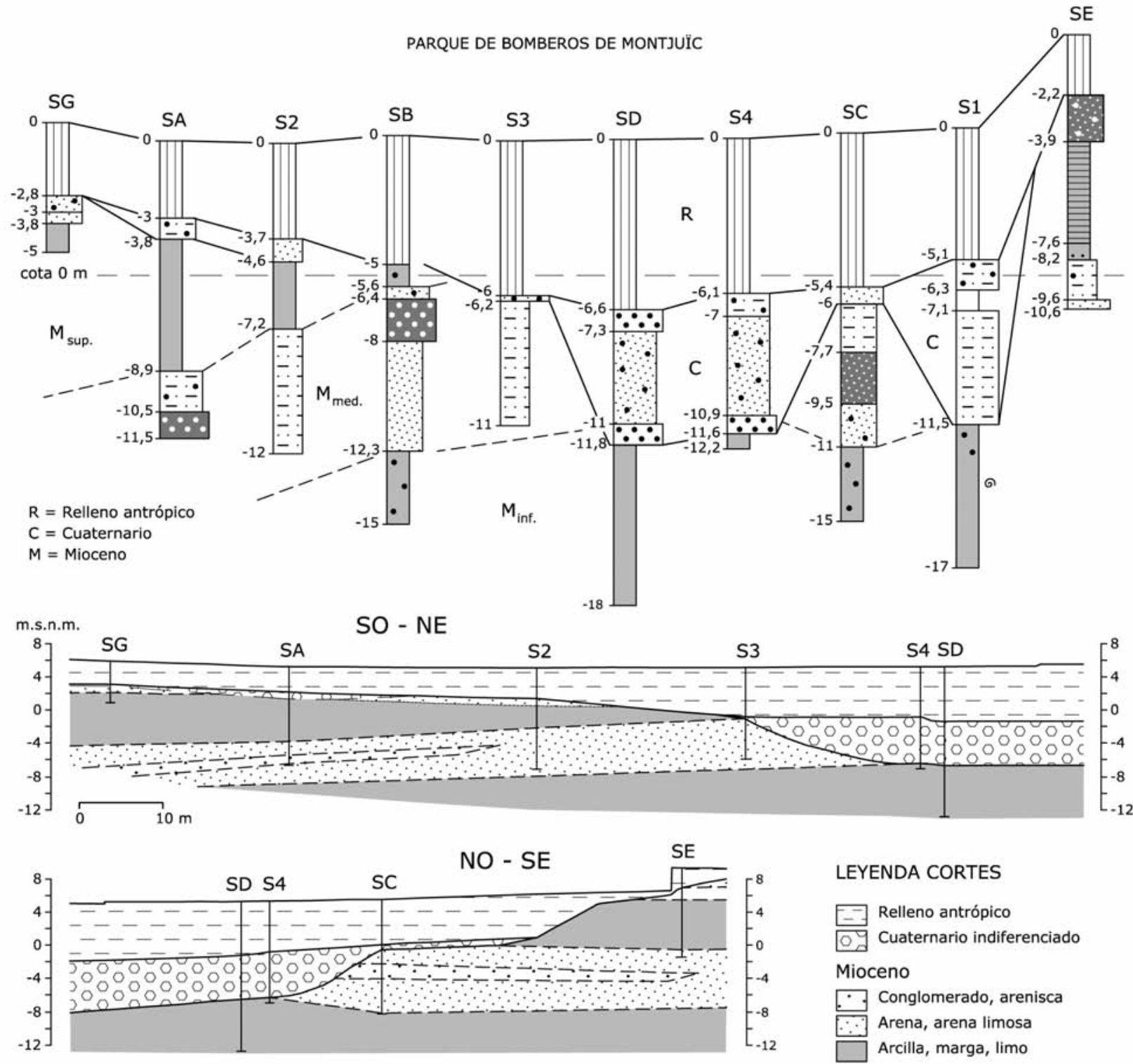

Fig. 10.-Correlación de sondeos del parque de bomberos de Montjuïc, adaptado de Bosch \& Ventayol (2008). Ver la figura 7 para la leyenda de las columnas y la figura 6 para la situación de los sondeos.

\section{Sondeos del Mirador del Alcalde y del túnel de Miramar}

Las partes superiores de los sondeos del mirador del Alcalde cortan una cobertera cuaternaria de hasta 11 metros de espesor, compuesta por limo y arena limosa, de color ocre, con nódulos de carbonato (Fig. 8). La base incluye un nivel con cantos rodados de arenisca, del orden de 1 metro de espesor. Por debajo, se identifica una serie miocena formada por capas de marga, arena o arenisca, y grava o conglomerado, con la misma tendencia cíclica que la observada en los sondeos del castillo. Destaca un tramo margoso de 15,2 $\mathrm{m}$ de espesor en el sondeo NS4 que representa la parte inferior de un ciclo que alcanza 27,7 $\mathrm{m}$ de espesor en este mismo sondeo. La parte superior de este ciclo está compuesta por un tramo intermedio de arena y arenisca, y un nivel de conglomerado a techo. Por encima se registran niveles de limo y arena limosa que corresponderían a otro ciclo parcialmente erosionado y cubierto por el cuaternario. En el sondeo NS4, por debajo de la marga se corta una capa de conglomerado bioclástico que correspondería al techo de un ciclo inferior. 


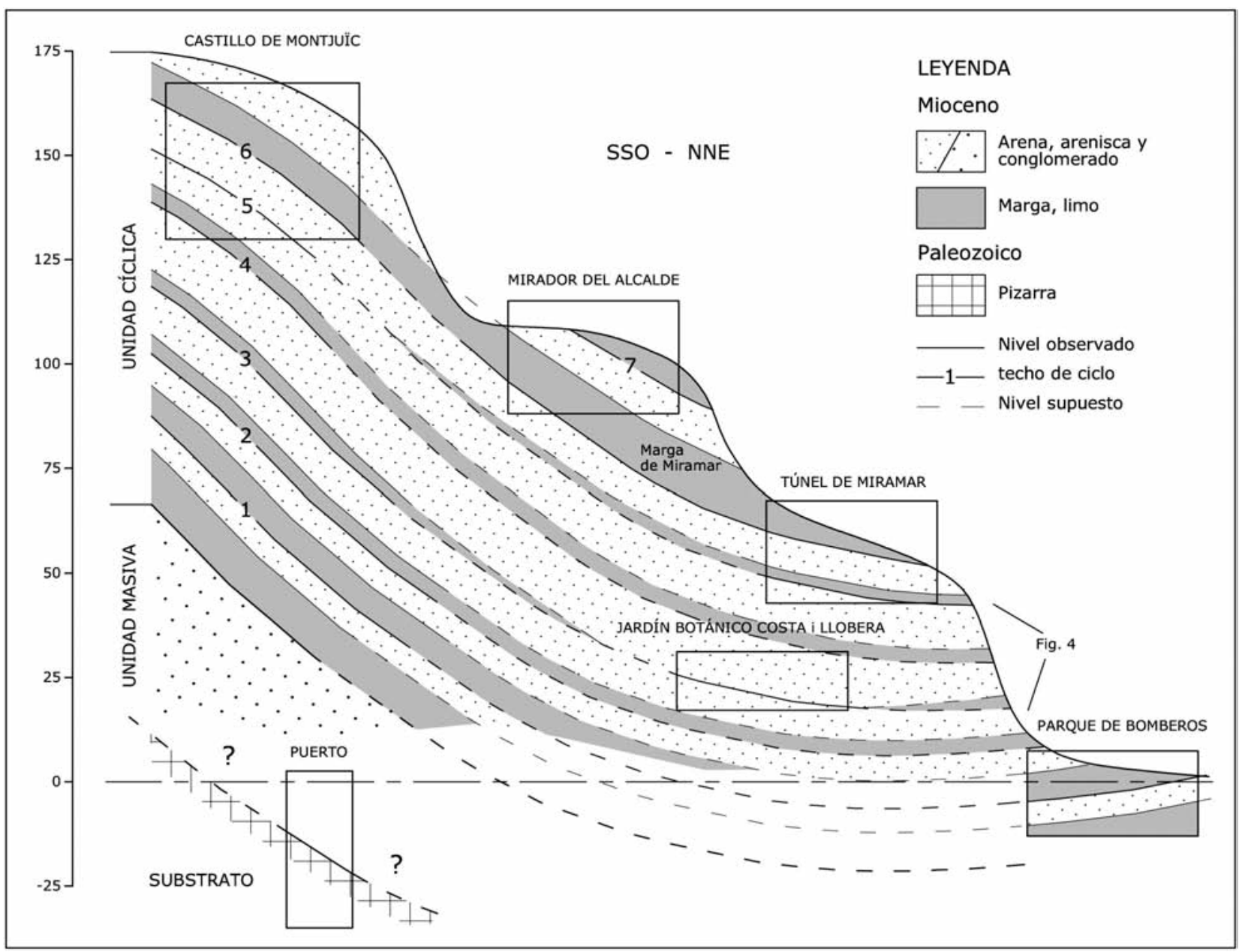

Fig. 11.-Corte litoestratigráfico esquemático del Mioceno del sector oriental de Montjuïc, a partir de la correlación de sondeos detallados en las figuras 7, 8, 9 y 10.

Esta serie se correlaciona fácilmente con los materiales expuestos en el acantilado por debajo del mirador (Fig. 5B). El tramo margoso de 15,2 m equivale al nivel f (Unidad Miramar de GómezGras et al., 2001). La arena, arenisca y conglomerado por encima de esta marga equivalen a la parte alta del acantilado (niveles g y h) (Unidad Mirador). El conglomerado basal corresponde al nivel e (techo de la Unidad Castell).

En los sondeos del túnel de Miramar se reconoce un depósito superior cuaternario, compuesto principalmente por limos ocres y rojizos, que se extiende hasta $8,2 \mathrm{~m}$ de profundidad en el sondeo $\mathrm{S} 1$, y una serie miocena inferior formada por capas de marga, arena margosa, arenisca y conglomerado con similar tendencia cíclica que en los casos anteriores. El sondeo S4 es el que tiene un registro más completo. En él se identifican tres ciclos: el techo de un ciclo inferior entre -24,2 y -30 m, compuesto por arenisca; un segundo ciclo completo, formado por un nivel basal de marga, un nivel intermedio de arenisca, y un nivel superior de conglomerado, entre -18,5 y $-24,2 \mathrm{~m}$; y la parte inferior de un tercer ciclo, entre $-3,7$ y $-18,5 \mathrm{~m}$, compuesto por marga y arena margosa bioclástica.

La correlación de esta serie con los materiales expuestos en el acantilado es también obvia. El tramo margoso superior de $15 \mathrm{~m}$ de espesor correspondiente a la marga de Miramar. Los materiales por debajo de esta marga equivalen al tramo inferior de arenisca con la intercalación de marga (niveles a, b, c, d, e de la Fig. 5A). La correlación entre los sondeos del mirador del Alcalde y del túnel de Miramar es, por tanto, inmediata utilizando como nivel guía a la marga de Miramar (nivel f), identificada en ambas zonas. 


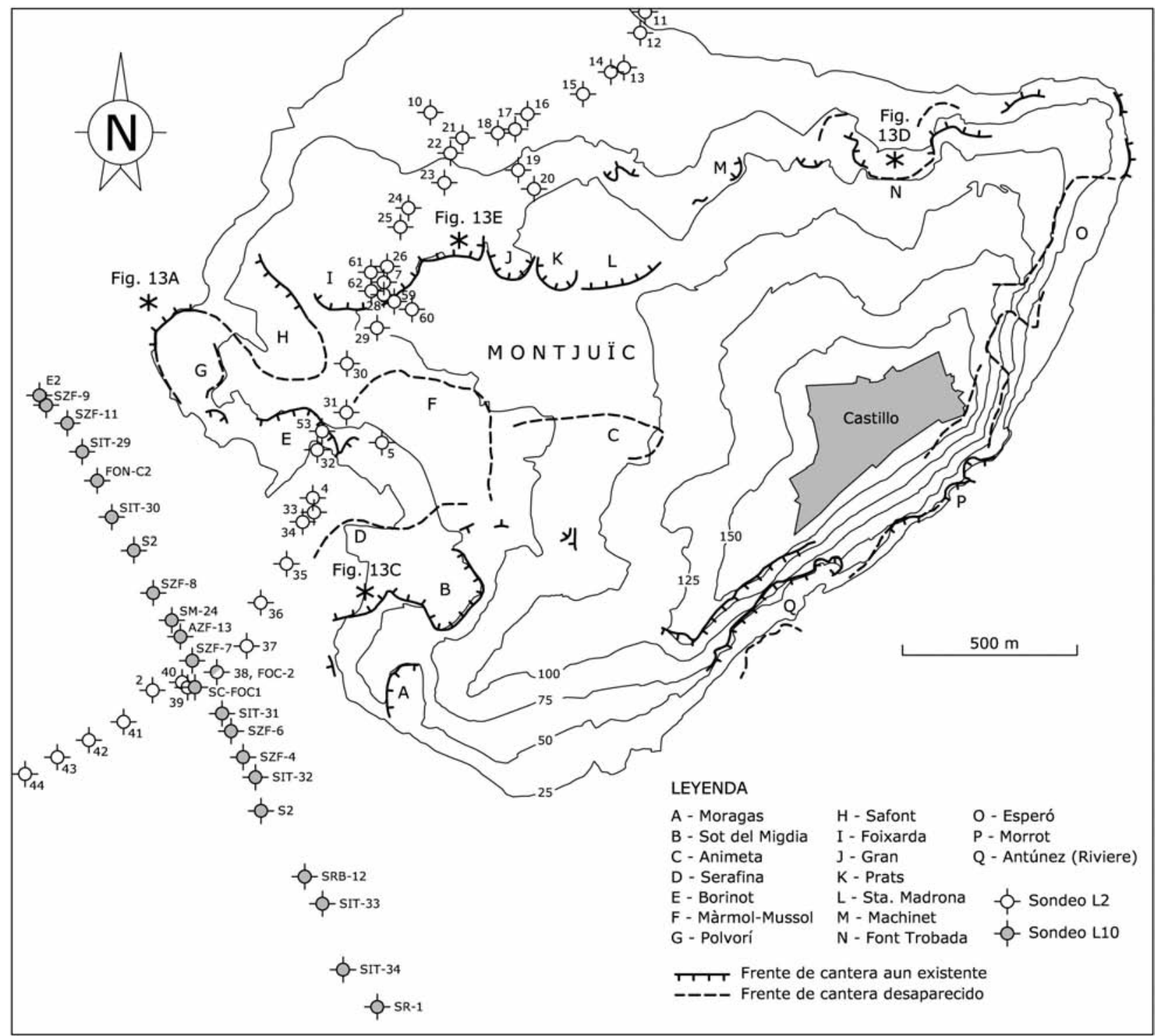

Fig. 12.-Mapa de Montjuïc con la localización de los sondeos estudiados del sector occidental y de las canteras.

La correlación de los sondeos del mirador del Alcalde con los sondeos del castillo es difícil de resolver con objetividad pues no hay continuidad de afloramiento ni tampoco ningún criterio estratigráfico claro que así lo permita. Se ha considerado que la marga de Miramar sería equivalente al tramo margoso superior de los sondeos del castillo, que en ambos casos (en el castillo y en el mirador) coincide en formar un principal tramo margoso de significativo mayor desarrollo que los otros tramos de marga observados (Fig. 7). Esta misma correlación es también la adoptada en el estudio de CCG (2009), y es coherente también con la cartografía de unidades litoestratigráficas de Parcerisa (2002, Fig. 4.1).

\section{Sondeos del jardín botánico Costa i Llobera}

Estos sondeos se han realizado sobre la antigua cantera del Esperó (Roca i Blanch, 2000) que tras su abandono fue rellenada con tierras y escombros, y posteriormente rehabilitada como jardín botánico, inaugurado en 1970. Los sondeos tienen longitudes entre 22 y $35 \mathrm{~m}$ y cortan dos diferentes unidades litológicas (Fig. 9): una unidad superior, de hasta 
21,2 m de espesor en el sondeo 4C, que correspondería al relleno de la antigua cantera del Esperó; y un substrato mioceno, de hasta 21,3 m de espesor en el sondeo 3P. El contacto entre los dos materiales constituye una superficie erosiva muy irregular, con desniveles de hasta $15 \mathrm{~m}$ entre sus cotas más baja y más alta. Este substrato mioceno llega a aflorar en la parte central del jardín, formando una elevación del terreno donde se ubica el mirador de La Puntaire. El mirador se sitúa sobre un nivel de arenisca de varios metros de espesor que estaría estratigráficamente por encima de los niveles cortados por los sondeos.

El relleno constituye un depósito muy heterogéneo, compuesto principalmente por limo ocre y marga gris, que engloban abundantes bloques de arenisca y conglomerado del Mioceno (Fig. 9). Son bloques con tamaños desde algunos centímetros hasta más de $1 \mathrm{~m}$, principalmente acumulados en los niveles inferiores del depósito. La parte superior de este depósito es principalmente arenosa-limosa, con bloques menores de arenisca y con frecuentes restos vegetales.

El substrato Mioceno está compuesto por capas de arenisca y conglomerado, con algunos niveles subordinados de arena limosa o margosa. En líneas generales, estos materiales forman un tramo basal conglomerático grisáceo, y un tramo superior de arena o arenisca, de color ocre con algunos horizontes rojizos. El contacto entre los dos tramos se sitúa algo por debajo de la cota de los $20 \mathrm{~m}$, y forma una superficie ligeramente inclinada hacia el $\mathrm{NE}$, con un desnivel de $4 \mathrm{~m}$ entre los sondeos 9C y 1C más alejados de la zona (Fig. 9). El material mostrado por los sondeos no es suficiente para poder establecer tendencias de ciclicidad comparables a las observadas en los sondeos de la parte alta del acantilado.

\section{Sondeos del parque de bomberos de Montjuïc}

Los sondeos realizados para la construcción del parque de bomberos de Montjuïc por Bosch \& Ventayol (2008), permiten reconocer un substrato mioceno inferior $(\mathrm{M})$, un depósito cuaternario intermedio $(\mathrm{C})$, y un relleno antrópico superior $(\mathrm{R})$ (Fig. 10).

El substrato mioceno forma tres diferentes tramos litológicos: un tramo medio de arena media-gruesa que engloba niveles cementados de microconglomerado y arenisca, de color beige y de 6 a $8 \mathrm{~m}$ de espesor; y dos tramos margosos, inferior y superior, de color ocre, verde o gris.
El depósito cuaternario es de arena con niveles de grava y cantos rodados de arenisca o microconglomerado miocenos, con un tamaño de hasta $30 \mathrm{~cm}$. El techo de este depósito coincide aproximadamente con la cota $0 \mathrm{~m}$. La base forma una superficie de erosión (paleocanal) que corta los diferentes niveles miocenos antes descritos. El relleno antrópico llega a tener hasta $6 \mathrm{~m}$ de espesor. Recubre el depósito cuaternario y en algunos sondeos recubre directamente el substrato mioceno. Es un material heterogéneo, mezcla de arena, arcilla, grava, bloques de arenisca, y escombros.

La serie miocena está inclinada unos $5^{\circ}$ hacia el SO, con un sentido de buzamiento opuesto al observado en las otras zonas antes descritas. En relación con los datos de superficie antes expuestos, esta estructura corresponde al flanco septentrional del sinclinal de Miramar (Figs. 4 y 5D). Con la información disponible, una precisa correlación entre estas capas miocenas del parque de bomberos y las del jardín botánico es inviable.

\section{Sondeos del puerto de Barcelona}

Los sondeos S1 y S2 del puerto de Barcelona (Fig. 6) se realizaron a $3 \mathrm{~m}$ sobre el nivel del mar, con longitudes respectivamente de 36 y 37,2 m (Geopayma, 2010). En ambos casos, la serie atravesada es muy parecida: Los primeros 3,4 y 4,1 m corresponden a los materiales de construcción del muelle. Por debajo, y hasta una profundidad de $-25,4$ y $-26,6$ se corta una serie arenosa grisácea correspondiente al Cuaternario reciente. En esta serie se puede distinguir un tramo inferior de arena de grano fino-medio, limpia, con algunas gravas dispersas, de 10,5 y $9 \mathrm{~m}$ de espesor; un tramo intermedio de limo y arena fina limosa, de 7,6 y 9,3 m, de color grisáceo, marrón y negro; y un tramo arenoso superior, similar al inferior, de $4 \mathrm{~m}$ en ambos sondeos. Por debajo de estas arenas cuaternarias, y hasta el final del sondeo, se cortan pizarras con filones de cuarzo, correspondientes al Paleozoico. En los metros superiores, las pizarras están en avanzado estado de alteración. Hacia abajo gradualmente son más compactas y presentan fracturas.

Los depósitos cuaternarios de estos sondeos, así como los del parque de bomberos, son probablemente equivalentes laterales de las formaciones holocenas del Cagalell y del Raval, definidas por Riba \& Colombo (2009) en la zona de enlace entre 

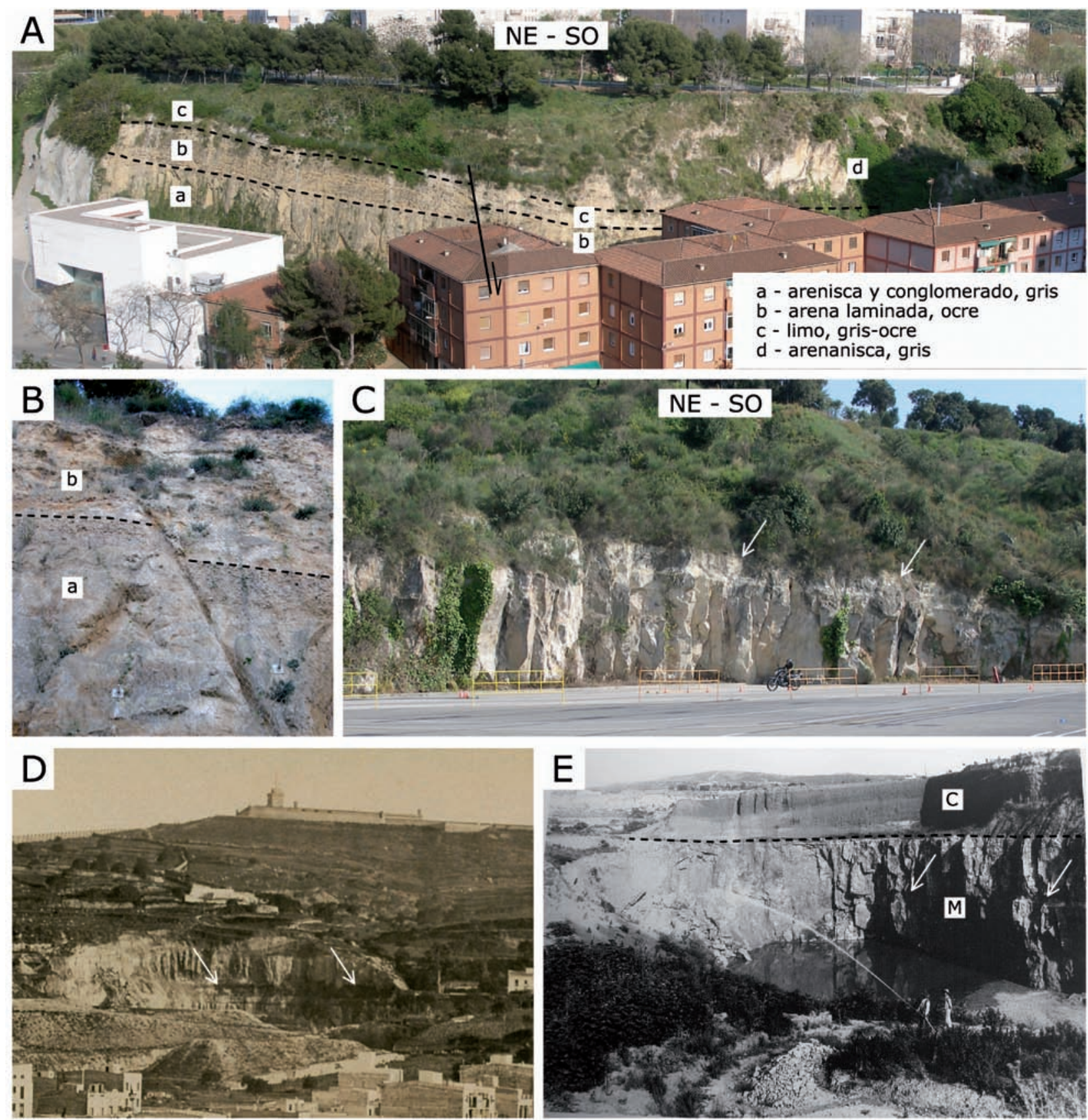

Fig. 13.-Afloramientos (canteras) representativos del sector occidental de Montjuïc: (A) cantera Safont. Las capas buzan 10 grados hacia el SO (flanco sur del anticlinal de Montjuïc). Afloran los ciclos 3 (niveles a,b,c) y parte basal del 4 (nivel d) de la unidad cíclica inferior; (B) detalle de la falla normal representada en la imagen anterior; (C) cantera del Sot del Migdia. Las flechas indican la estructura en capas inclinadas 7 grados hacia el SO (flanco sur del anticlinal de Montjuïc); (D) cantera de la Font Trobada, desaparecida tras la construcción de la piscina municipal de Montjuïc. Las flechas indican la estructura en capas horizontales. Detalle de una fotografía del siglo XIX realizada por J. Martí (1874); (E) cantera Foixarda. El frente de explotación permite distinguir la arenisca miocena $-\mathrm{M}$ - y la cobertera cuaternaria -C-. Las flechas indican la estructura en capas horizontales que en este caso representan la zona de charnela del anticlinal de Montjuïc. Ver la figura 12 para la localización de estos afloramientos.

el llano de Barcelona y Montjuïc. Esta zona fue una antigua bahía entre los relieves costeros de Montjuïc y del Taber (zona elevada de la catedral de Barcelona), que se fue rellenando de sedimentos lacustres y marinos hasta tiempos históricos recientes. En los sondeos Drassanes-1 y Colom, 


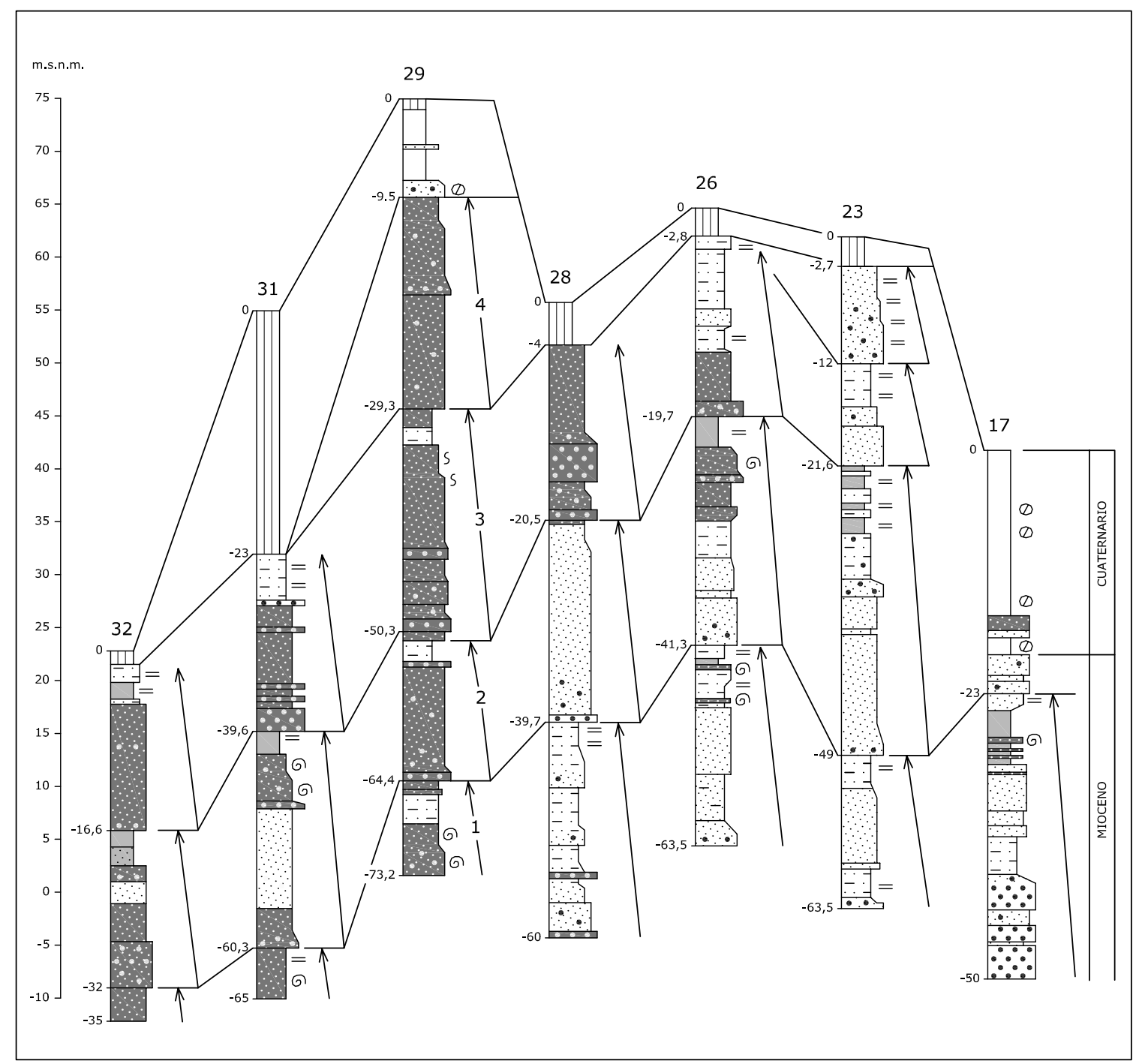

Fig. 14.-Correlación de algunos sondeos representativos de la Línea 2 en el sector occidental de Montjuïc. Ver la figura 7 para la leyenda de las columnas y la figura 12 para la situación de los sondeos.

descritos por estos autores, la base de estas formaciones se corta respectivamente en estos sondeos a -16 y $-20 \mathrm{~m}$ de profundidad, y han sido datadas mediante ${ }^{14} \mathrm{C}$ como holocenas.

\section{Litoestratigrafía del sector oriental}

La figura 11 muestra un corte litoestratigráfico de la zona abarcada por los sondeos del sector oriental. El corte reproduce la estructura del flanco septentrional del anticlinal de Montjuïc y su enlace con el sinclinal de Miramar, con un desarrollo idealizado de las unidades masiva y cíclica.
Según este corte, los materiales miocenos atravesados por los sondeos del parque de bomberos se corresponderían con los niveles inferiores de la unidad cíclica. El corte sugiere que podría tratarse de los dos ciclos basales de esta unidad, pero esta precisión es difícil de demostrar con la información disponible. En cualquier caso, serían materiales situados por encima de la unidad masiva que deja de aflorar unos $400 \mathrm{~m}$ al sur de estos sondeos.

Los depósitos miocenos atravesados por los sondeos del jardín botánico tendrían una posición estratigráfica más alta. El tramo basal de conglomerado representaría el techo de uno de los ciclos intermedios de la unidad cíclica. Los niveles de arena y are- 


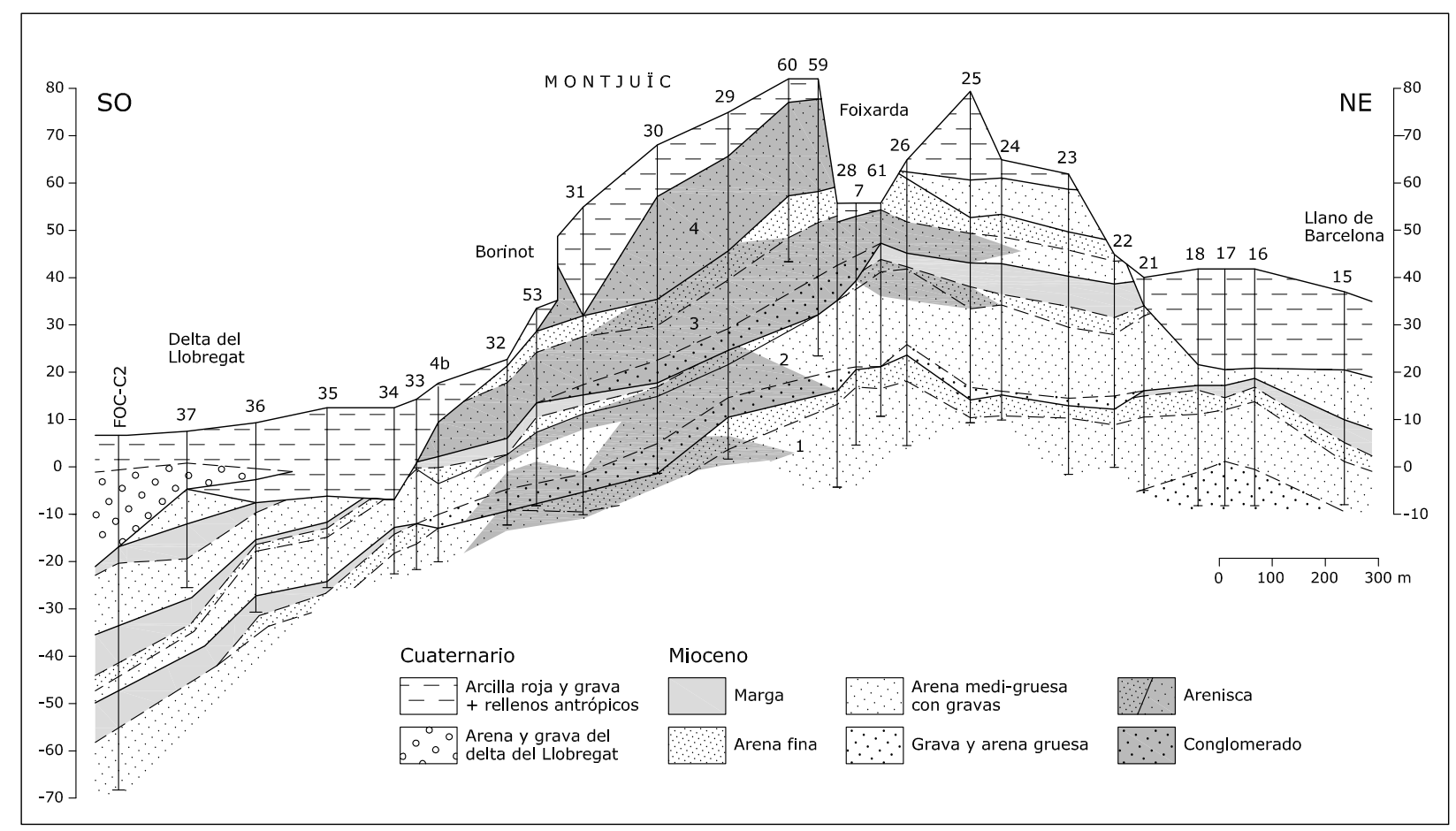

Fig. 15.-Corte del sector occidental de Montjuïc a partir de la correlación de los sondeos de la Línea 2. El sondeo FOC-C2, situado en el extremo izquierdo del corte corresponde a la Línea 10. Ver la figura 12 para la situación de los sondeos.

nisca superiores serían la parte basal de un ciclo superior. En este caso no se cortan niveles de marga propios de la base de los ciclos, reproduciendo una situación similar a la del sexto ciclos también sin marga basal registrado por los sondeos del castillo (Fig. 7). Los demás sondeos, tal como ya se ha expuesto anteriormente, cortan los cuatro ciclos superiores de la serie miocena.

\section{Sector occidental}

\section{Geología de superficie}

Los afloramientos de este sector corresponden principalmente a los frentes de explotación de antiguas canteras (Fig. 12). Las canteras de la vertiente sur de la montaña cortan el flanco SO del anticlinal de Montjuïc. La estructura de este flanco se aprecia especialmente bien en los cortes aproximadamente perpendiculares al pliegue de las canteras Safont (Fig. 13A) y del Sot del Migdia (Fig. 13C). En ambas canteras las capas de arenisca se observan inclinadas hacia el SO, con buzamientos entre 5 y 10 grados. La inclinación de las capas va asociada a pequeñas fallas normales con la misma vergencia hacia el SO (Fig. 13B). Los frentes de las canteras de la vertiente norte de la montaña están principalmente orientados en la dirección E-O, subparalelos al flanco norte del anticlinal. Por ello, las capas de arenisca se observan prácticamente horizontales (Fig. 13 D y E) y no se tiene perspectiva de la inclinación de este flanco septentrional.

\section{Sondeos de la Línea 2 del Metro de Barcelona}

Los sondeos de la Línea 2 cortan capas de grava, conglomerado, arena, arenisca y marga, hasta una profundidad del orden de 10 m.b.n.m., sin llegarse a alcanzar en ningún caso el substrato de la serie miocena (Figs. 14 y 15). Los materiales son similares a los observados en el sector oriental antes descritos. Sin embargo, en este caso se disponen formando ciclos granodecrecientes, del orden de 20 $\mathrm{m}$ de espesor. Un ciclo completo ideal estaría compuesto por un tramo basal de grava y arena gruesa (o conglomerado); un segundo tramo de arena (o arenisca), principalmente de grano medio-grueso, con niveles subordinados de grava; un tercer tramo de arena fina limosa, generalmente rica en bioclastos marinos (conchas de bivalvos y gasterópodos); 
y un tramo superior margoso, con niveles subordinados de arena o arenisca de grano fino y ocasionalmente también niveles calcáreos. La base de estos ciclos constituye una superficie erosiva que corta parte de los tramos de arena fina y marga del techo del ciclo subyacente (Fig. 15). La cementación afecta principalmente a los depósitos de textura más gruesa (grava, arena gruesa), y de forma más variable a los de arena media o fina. La geometría de estos niveles cementados es muy irregular, con rápidos cambios laterales y verticales hacia niveles inconsolidados. En líneas generales, cada ciclo tiende a formar un gran lentejón de arenisca y conglomerado que se acuña lateralmente entre los materiales inconsolidados hacia los márgenes de la montaña (Fig. 15). En el subsuelo de los llanos periféricos de Barcelona y del delta del Llobregat los depósitos miocenos están, salvo alguna excepción, sin cementar.

Se reconocen 4 ciclos granodecrecientes principales que se correlacionan bien entre los diferentes sondeos, con un espesor total próximo a los $80 \mathrm{~m}$ (Figs. 14 y 15). Cada uno de estos ciclos principales incluye ciclos de rango menor, también de carácter granodecreciente, que generalmente no llegan a correlacionarse entre los sondeos continguos (paleocanales). Los dos ciclos inferiores (1 y 2) muestran una sucesión granodecreciente completa, con los cuatro tramos litológicos bien desarrollados. Los dos ciclos superiores ( 3 y 4 ) son de carácter arenoso más uniforme. El cuarto ciclo constituye el relieve principal del sector occidental de Montjuïc, sobre el que se han excavado las canteras. Los ciclos inferiores afloran sólo localmente. Pueden intepretarse como ciclos aluviales retrogradantes que evolucionan desde una llanura aluvial relativamente proximal (gravas basales), hacia una llanura aluvial distal o deltaica (arenas con paleocanales de grava), después hacia depósitos marinos someros (arenas bioclásticas) y finalmente depósitos marinos más profundos (margas).

La correlación de los sondeos de la Línea 2 pone de evidencia la estructura anticlinal de Montjuïc (Fig. 15). La charnela de este pliegue se situaría en el tramo de areniscas explotadas en la cantera Foixarda (Fig. 13E). El corte muestra una marcada asimetría en la distribución de los materiales cementados con respecto a los inconsolidados. Así, las principales capas de areniscas y conglomerados están del lado del flanco SO del pliegue. En el flanco NE dominan los niveles de arena y grava.

\section{Sondeos de la Línea 10 del Metro de Barcelona}

A lo largo del margen meridional de Montjuïc, los sondeos realizados para la construcción de la Línea 10 del Metro de Barcelona registran cuatro principales unidades sedimentarias (Fig. 16):

Unidad basal de arcillas rojas-versicolores con abundantes gravas metamórficas, correspondientes al Mioceno Inferior (depósitos aluviales burdigalienses). Forman una monótona sucesión de hasta 20,4 m de espesor en el sondeo FON-C2, sólo cortada por los sondeos del extremo NO del paseo de la Zona Franca. Estos sondeos en ningún caso alcanza la base de esta unidad. No obstante, otros sondeos de la Línea 10 más alejados de Montjuïc (en Les Corts) si llegan a cortar la base de esta unidad que se dispone discordante sobre rocas paleozoicas. El techo constituye una superficie erosiva, inclinada hacia el SE, que constituyen el substrato del Mioceno de Montjuïc en la parte occidental de la montaña.

Unidad de arenas grises y ocres, con gravas silíceas y niveles subordinados de marga, correspondientes al Mioceno Medio de Montjuïc. Forman un cuerpo de espesor creciente hacia el SO, limitado por supeficies erosivas. La mayor parte de los sondeos penetran pocos metros en esta unidad y en ellos resulta difícil poder precisar su estratigrafía. Los sondeos que atraviesan un mayor espesor de esta unidad muestran una estructura en ciclos granodecrecientes similares a los observados en los sondeos de la Línea 2. La estructura sedimentaria sugiere que las arenas de esta unidad onlapan la superficie erosiva basal.

Unidad de arcillas rojas con capas de gravas metamórficas y arenas limosas, equivalente al Cuaternario antiguo del llano de Barcelona (Pleistoceno aluvial). A diferencia del Burdigaliense, estos sedimentos muestran una estructura en capas bien diferenciadas. La parte inferior de esta unidad forma un tramo masivo de gravas de gran tamaño. Por encima forma una serie principalmente arcillosa, con un variable grado de desarrollo de las capas de arena y grava según los sondeos. En conjunto forma una serie con tendencia granodecreciente. La base constituye una superficie erosiva excavada sobre el Mioceno de Montjuïc, con morfología acanalada.

Unidad superior de arenas, gravas y limos correspondientes al Cuaternario reciente (Holoceno) del delta del Llobregat. Se identifican dos diferentes tramos litológicos: un tramo inferior compuesto por 

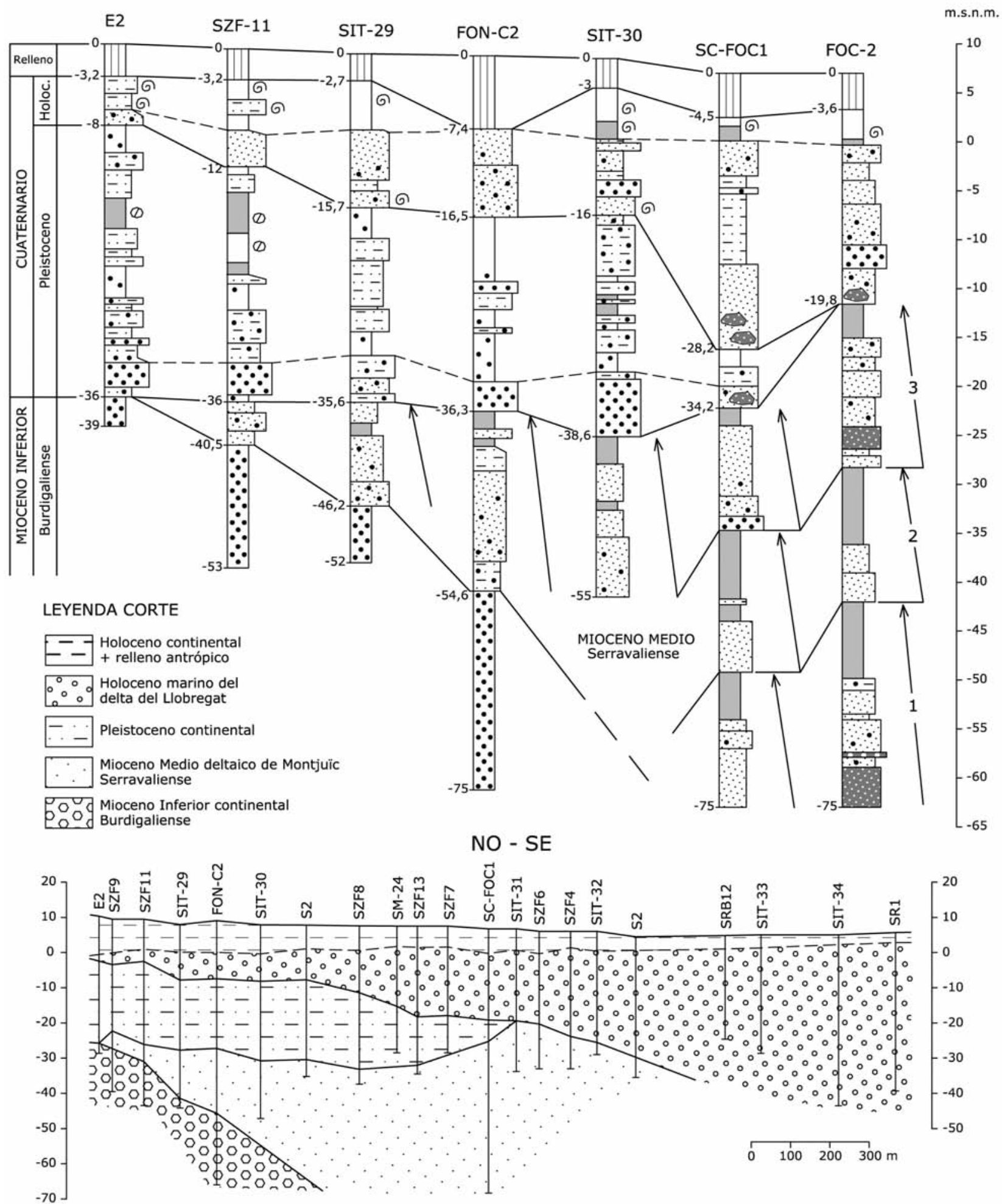

Fig. 16.-Correlación de algunos sondeos representativos de la Línea 10 y corte a lo largo del paseo de la Zona Franca. Ver la figura 7 para la leyenda de las columnas y la figura 12 para la situación de los sondeos. 
arenas i gravas limpias (sin matriz fina), que forma un cuerpo sedimentario que aumenta de espesor hacia el SE, hasta superar los $50 \mathrm{~m}$ de espesor en la zona del puerto de Barcelona; y un tramo superior arcilloso, marrón, con frecuentes restos de conchas de gasterópodos continentales, de hasta $7 \mathrm{~m}$ de espesor, que se acuña hacia el SE. La base de esta unidad es una nueva superficie erosiva, inclinada hacia el SE que, en este mismo sentido, corta primero al Cuaternario antiguo y después al Mioceno de Montjuïc.

\section{Correlación entre sectores e implicaciones estructurales}

En el estudio de Villalta \& Rosell (1965) se presenta una correlación de perfiles estratigráficos representativos del conjunto de la montaña de Montjuïc. En esta correlación se considera el tramo de arenisca explotado por las canteras del sector occidental (ciclo 4 de la Fig. 15) equivalente al tramo de arenisca más alto de la serie de El Morrot. Esta correlación se basa en el hecho de que el tramo de arenisca explotado por las canteras de la vertiente norte de Montjuïc se puede seguir cartográficamente hasta la zona de Miramar, donde enlazarían con los niveles de arenisca justo por debajo de la marga de Miramar. Esta marga y areniscas subyacentes, como ya se ha expuesto anteriormente, hacia el sur suben de cota hasta situarse debajo del castillo. Por la parte sur de la montaña, la correlación es inviable debido a la amplia discontinuidad de afloramiento que supone la zona cubierta por el cementerio del Suroeste.

Si se acepta esta correlación entonces la serie compuesta por ciclos granocrecientes del perfil de El Morrot debería ser equivalente a la serie compuesta por ciclos granodecrecientes cortada por los sondeos de la Línea 2. Por otro lado, la unidad masiva de El Morrot no estaría representada en el sector occidental pues en este sector la serie compuesta por ciclos granodecrecientes tiene continudad hasta el substrato burdigaliense. Ambos aspectos estratigráficos son difíciles de explicar.

Los datos sugieren que los dos sectores podrían constituir dos bloques miocenos independientes separados por una falla. Se trataría de una falla lístrica, de dirección NE-SO, que habría producido el hundimiento del bloque oriental de Montjuïc con respecto al occidental y a la vez su basculamiento hacia el NO (Fig 17). En el bloque occidental ten- dríamos representada la parte inferior de la serie miocena de Montjuïc, que formaría una unidad cíclica inferior de carácter esencialmente aluvial, desarrollada sobre un substrato burdigaliense. En el bloque oriental hundido tendríamos la parte superior de la serie miocena, compuesta por una unidad masiva aluvial y una unidad cíclica superior deltaica. La unidad masiva de El Morrot podría ser equivalente al tramo superior de arenisca del sector occidental ( $4^{\circ}$ ciclo) pues en ambos casos forman un principal tramo de arenisca de similares características. En el subsuelo del bloque oriental, por debajo de la unidad masiva de El Morrot podríamos tener los niveles equivalentes laterales de la unidad cíclica inferior. El substrato paleozoico cortado por los sondeos del puerto sugiere que en esta parte de Montjuïc no estarían representados los depósitos burdigalienses, que podrían haber sido erosionados previamente a la sedimentación del Mioceno de Montjuïc.

La rotación del bloque oriental hundido permitiría explicar el basculamiento observado hacia el NO de las unidades masiva y cíclica superior (este basculamiento no se manifiesta en el sector occidental) y la formación del sinclinal de Miramar. Este sinclinal sería una estructura dúctil asociada al labio del bloque hundido, del tipo gancho de falla. Esta interpretación es coherente con la dirección NE-SO del eje del sinclinal cartografiada por Geotec-262 (2001) en la zona de Miramar.

El anticlinal de Montjuïc se reconoce con características similares en los dos sectores, y sería una estructura originada con anterioridad a la falla de Miramar. Es un suave pliegue de dirección NO-SE, difícil de explicar en un contexto tectónico extensional como el ocurrido a lo largo del Mioceno. Para esta estructura se puede interpretar un origen sin-sedimentario. El anticlinal podría ser el resultado de una compactación diferencial entre los depósitos miocenos precozmente cementados que forman principalmente el núcleo del pliegue, y los depósitos inconsolidados que forman sus flancos. Según Parcerisa et al. (2001), esta cementación es de origen diagenético temprano, y tuvo lugar en condiciones de muy poca profundidad, antes de la compactación del sedimento. Así, para una misma capa, la parte cementada habría mantenido su volumen original mientras que las partes laterales sin cementar habrían disminuido de volumen como resultado de la compactación durante su enterramiento. La repetición de este proceso en las diferentes capas podría haber sido la causa del anticli- 


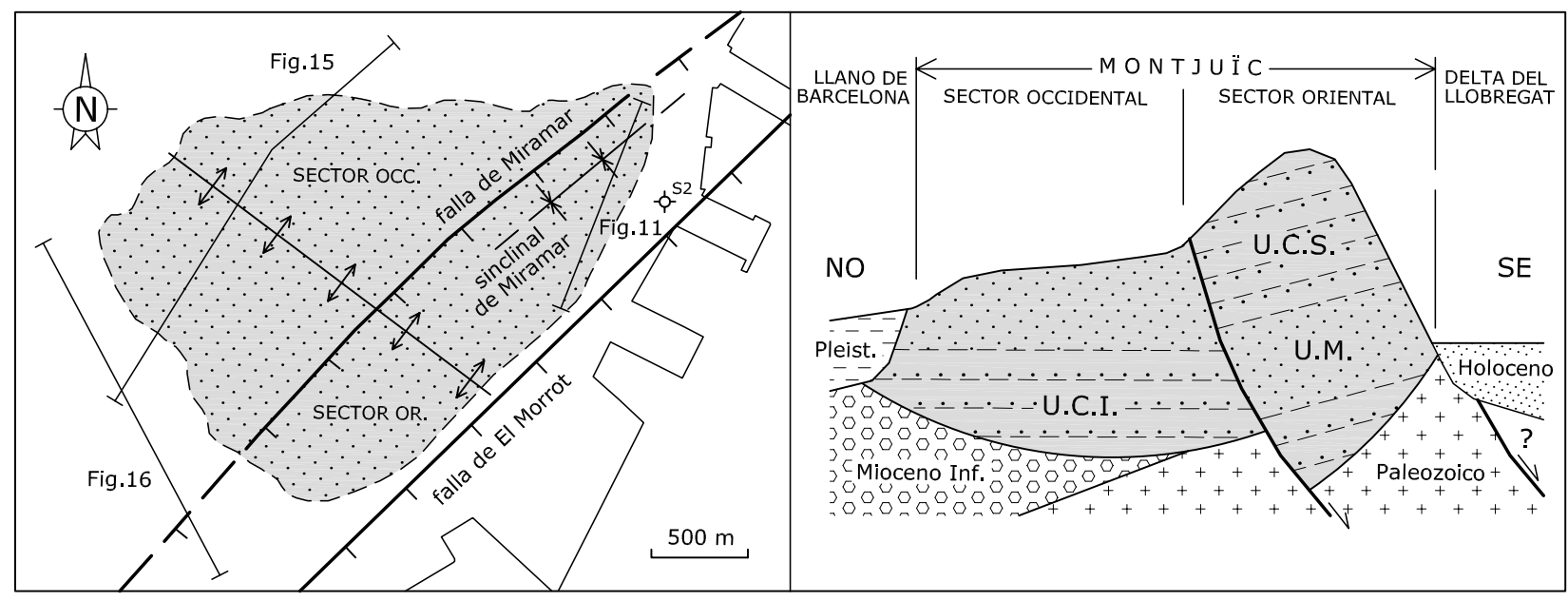

Fig. 17.-Mapa y corte esquemático interpretativo de la estructura y principales unidades litoestratigráficas del Mioceno de Montjuïc. U.C.I. = unidad cíclica inferior, U.M. = unidad masiva, U.C.S. = unidad cíclica superior .

nal. El sistema de diaclasas y pequeñas fallas normales de dirección principalmente NO-SE que se identifican en los afloramientos de arenisca y conglomerado, pueden interpretarse como el resultado del comportamiento frágil de estos materiales durante la formación del pliegue. Son fracturas que se identifican tanto en los flancos como en la charnela del pliegue y que están normalmente abiertas y rellenas de minerales filonianos (calcedonia, calcita, etc.) y también de arcillas cuaternarias.

Tras el plegamiento y posterior fracturación, la montaña de Montjuïc sería el resultado de la erosión diferencial entre los niveles cementados más duros y resistentes a la erosión, y los inconsolidados más blandos y erosionables. El relieve invertido que forma la falla de Miramar (el bloque hundido es el que da el relieve más elevado) podría ser también un efecto de erosión diferencial si se considera que las capas de arenisca de la parte superior de la montaña atravesadas por los sondeos del castillo, debieron pasar lateralmente hacia el oeste a niveles más blandos.

La falla de Miramar propuesta en este estudio podría ser una estructura de origen similar a la falla de El Morrot (Fig. 1). Ambas formarían parte del sistema de fallas normales que han afectado el margen litoral catalán durante el Neógeno (Bartrina et al., 1992). No hay indicios para pensar que estas fallas hayan podido ser activas durante el cuaternario pues los sedimentos de este periodo las fosilizan y aparentemente no muestran ningún tipo de deformación. La falla de El Morrot se ha venido situando adosada al pie del acantilado de Montjuïc, inter- pretadose éste como un escarpe de falla. El substrato paleozoico cortado por los sondeos del puerto obliga a desplazar esta falla hacia el este. En este sentido, el acantilado oriental de Montjuïc (como mínimo la parte entre el espolón de El Morrot y Miramar) no puede ser considerado como un escarpe de falla, sino como un escarpe erosivo ligado a una dinámica costera regresiva.

\section{Conclusiones}

El análisis y correlación de los sondeos estudiados, conjuntamente con los datos aportados por la geología de superficie, permiten concluir que la montaña de Montjuïc sería el resultado de la siguiente sucesión de procesos geológicos:

(1) El Mioceno de Montjuïc empieza a sedimentarse sobre una superficie de erosión intra-miocena desarrollada sobre rocas metamórficas paleozoicas y detríticas del Mioceno Inferior (burdigalienses).

(2) En una primera etapa la sedimentación fue esencialmente aluvial. Se indentifican 4 ciclos aluviales principales con espesores del orden de $20 \mathrm{~m}$ cada uno de ellos, que componen el sector occidental de Montjuïc (unidad cíclica inferior) y también los niveles basales del sector oriental (unidad masiva). Son ciclos que representan un sistema aluvial retrogradante, que evolucionan hacia techo desde depósitos de llanura aluvial (gravas y arenas medias-gruesas) hacia depósitos litorales someros (arenas finas bioclásticas) y finalmente marinos relativamente profundos (margas grises). 
(3) En una segunda etapa, la sedimentación fue esencialmente deltaica. Se identifican 7 ciclos deltaicos con espesores de 15 a $20 \mathrm{~m}$ cada uno de ellos, que componen principalmente el sector oriental de Montjuïc (unidad cíclica superior). Son ciclos que representan un sistema deltaico progradante, que evolucionan hacia techo desde depósitos margosos prodeltaicos hacia depósitos arenosos de frente delaico, y de arena y gravas de llanura deltaica.

(4) De forma coetánea con la sedimentación se desarrolla una estructura antiformal de dirección NO-SE. Esta estructura sería el resultado de la compactación diferencial entre los sedimentos aluviales y deltaicos precozmente cementados y los inconsolidados.

(5) Finalizada la sedimentación se generan las fallas de Miramar y El Morrot, que hunden escalonadamente parte del Mioceno de Montjuïc hacia la cuenca mediterránea. Asociado a este hundimiento se genera el sinclinal de Miramar, que sería una estructura menor subordinada al bloque hundido adosada a la falla del mismo nombre.

(6) A partir del Mioceno superior, los depósitos miocenos de Montjuïc entran en una fase de progresiva erosión que se prolonga hasta la actualidad. La montaña será el resultado de la erosión diferencial entre los materiales bien cementados (principales capas de arenisca y conglomerado), más duros y resistentes a la erosión, y los inconsolidados (arenas, gravas y margas), localizados respectivamente en el núcleo y flancos del anticlinal sin-sedimentario.

(7) Esta fase de erosión va asociada al desarrollo de una cobertera coluvial cuaternaria que cubrirá buen parte de la montaña y fosilizará sus diferentes estructuras.

\section{AGRADECIMIENTOS}

El autor quiere agradecer a Jordi Jubany y Laura Carrasco, del Departament de Política Territorial i Obres Públiques de la Generalitat de Catalunya; Carles Teixidor y Àngel López, de BIMSA; Albert Ventayol, de Bosch \& Ventayol Geoserveis; Pere Valero y Laura Blanco, de Geotec-262; Enrique Fernández y Maite Castellá, de Geopayma; Marta Filbà, de Paymacotas; Eva Vázquez y Pere Sarbós, de G3; y Teodoro González, del Centro Catalán de Geotecnia, la ayuda prestada en la revisión de los testigos de los sondeos. También agradece a GISA (Gestió d'Infraestructures SA, de la Generalitat de Catalunya), BIMSA (Barcelona d'Infraestructures Municipals SA), Parcs i Jardins de l'Ajuntament de Barcelona, Societat Municipal d'Aparcaments i Serveis SA de l'Ajuntament de Barcelona, y a la Autoridad Portuaria de Barcelona, los permisos facilitados para el estudio de los sondeos y la consulta de los correspondientes informes geotécnicos. Igualmente, agradece a Lluís Cabrera, de la Facultat de Geologia de la Universitat de Barcelona, y a Antonio Casas, del Departamento de Ciencias de la Tierra de la Universidad de Zaragoza, la revisión crítica del manuscrito.

\section{Referencias}

Almera, J. (1899). Compte rendu de l'excursion du 28 septembre à Sans et à Montjuich. Bulletin de la Societé Géologique de France, ser. III, 26: 680-689.

Bartrina, M.T.; Cabrera, L.; Jurado, M.J.; Guimerà, J. \& Roca, E. (1992). Evolution of the central Catalan margin of the Valencia trough (western Mediterranean). Tectonophysics, 203: 219-247

Beuter-Blasco (2007a). Estudi geològic-geotècnic dels Jardins de Mossèn Costa i Llobera, Montjuïc (Barcelona). Parcs i Jardins, Ajuntament de Barcelona. Informe inédito.

Beuter-Blasco (2007b). Projecte executiu d'auscultació de la vessant del parc de Mossèn Costa i Llobera. Parcs i Jardins, Ajuntament de Barcelona. Informe inédito.

Bosch \& Ventayol (2007). Estudi geotècnic de l'estabilitat dels talussos del Mirador de l'Alcalde. Montjuïc. Barcelona. Informe inédito.

Bosch \& Ventayol (2008). Estudi geotècnic per la construcción del Parc de Bombers a l'accés de la Porta Forestier de Montjü̈c. Edifici de l'Speis el Port. Departament de Logística i Infraestructures, Ajuntament de Barcelona. Informe inédito.

Carez, L. (1881). Etude des terrains cretacés et tertiaires du Nord de l'Espagne. Tesis Doctoral, Paris, 327 pp.

CCG (2009). Estudi Geològic i Geotècnic del terreny on s'emplaça el Castell de Montjuïc. Barcelona d'Infraestructures Municipals SA. Informe inédito.

Colom, G. \& Bauzá, J. (1945). Notas sobre los foraminíferos de las margas Miocénicas de Montjuich. Boletín de la Real Sociedad Española de Historia Natural, 43, 9-10: 483-498

Faura y Sans, M. (1917). Montjuich notas geológicas. Boletín de la Sociedad de Atracción de Forasteros, 28: 6-55

Gàmez, D. (2007). Sequence stratigraphy as a tool for water resources Management in alluvial coastal aquifers: application to the Llobregat delta (Barcelona, Spain). Tesis Doctoral, Universitat Politècnica de Catalunya, $177 \mathrm{pp}$.

Geopayma (2010). Estudio geotécnico para la cimentación de un puente en el Muelle de Costa (Puerto de Barcelona). Autoridad Portuaria de Barcelona. Informe inédito.

Geotec-262 (2001). Estudi geotècnic realitzat a la zona de Miramar per la construcció d'un vial d'accés des de la carretera de Miramar a la plaça Carlos Ibáñez de Montjuïc, Barcelona. Societat Municipal d'Aparcaments i Serveis, Ajuntament de Barcelona. Informe inédito. 
Gimeno, A. \& Padreny, J. (1947). Notas estratigráficas y paleontológicas sobre el Vindoboniense de Montjuich. Boletín de la Real Sociedad Española de Historia Natural, 45: 551-559

GISA (2002). Línia 9 del Metro de Barcelona, tram 2n: Parc Logístic - Zona Universitària. Projecte constructiu. Departament de Política Territorial i Obres Públiques de la Generalitat de Catalunya. Informe inédito.

GISA (2007). Perllongament de la Línia 2 de l'FMB entre Sant Antoni i Parc Logístic (connexió L9). Projecte constructiu. Departament de Política Territorial i Obres Públiques de la Generalitat de Catalunya. Informe inédito.

Gómez-Gras, D.; Parcerisa, D. Bitzer, K.; Roca, E. \& Thiry, M. (2000). Hydrogeochemistry and diagenesis of Miocene sandstones at Montjuïc, Barcelona (Spain). Journal of Geochemical Exploration, 69-70: 177-182

Gómez-Gras, D.; Parcerisas, D.; Calvet, F.; Porta, J.; Solé de Porta, N. \& Civis, J. (2001). Stratigraphy and petrology of the Miocene Montjuïc delta (Barcelona, Spain). Acta Geológica Hispánica, 36: 115-136

G3 (2012). Reconeixement geològic/geotècnic dels terrenys per a les obres corresponents al projecte basic d'obra civil del nou centre d'instal.lacions tècniques del castell de Montjü̈, Barcelona. Barcelona d'Infraestructures Municipals SA. Informe inédito.

ICC (2005). Mapa Geològic Comarcal de Catalunya 1:50.000, 13 Barcelonès. Institut Cartogràfic de Catalunya.

Llopis Lladó, N. (1942a). Los terrenos cuaternarios del llano de Barcelona. Publ. Instituto Geológico-Topográfico de la Diputación Provincial de Barcelona, 6: 5-52

Llopis Lladó, N. (1942b). Tectomorfología del macizo del Tibidabo y valle inferior del Llobregat. Estudios Geográficos, 3, 321-383.

Magné, J. (1978). Etudes microstratigraphiques sur le neogène de la Méditerranée Nord-Occidentale. Les bassins neogenes catalans. Tesis Doctoral. Université Paul Sabatier, Toulouse, 260 pp.

Marqués, M.A. (1984). Les formacions quaternàries del delta del Llobregat. Institut d'Estudis Catalans, Barcelona, $281 \mathrm{pp}$.

Martí, J. (1874). Bellezas de Barcelona. Relación fotografiada de sus principales monumentos, edificios, calles, paseos y todo lo mejor que encierra la antigua capital del principado. Ed. Vives (documento incunable).

Parcerisa, D. (2002). Petrologia i diagènesi en sediments de l'Oligocè superior $i$ del Miocè inferior $i$ mitjà de la Depressió del Vallès i del Pla de Barcelona. Evolució de l'àrea font $i$ dinàmica dels fluids. Tesis Doctoral, Universitat Autònoma de Barcelona, 288 pp.

Parcerisa, D.; Thiry, M.; Gómez-Gras, D. \& Calvet, F. (2001). Proposition d'un modèle de silicification superficielle des grès néogènes de Montjuïc, Barcelone (Espagne): paragenèse minérales, environnements géo- chimiques et circulation des fluides. Bulletin de la Societé Géologique de France, 172: 751-764.

Parcerisa, D.; Gàmez, D.; Gómez-Gras, D.; Usera, J.; Simó, J.A. \& Carrera, J. (2008). Estratigrafía y petrología del subsuelo precuaternario del sector SW de la depresión de Barcelona (Cadenas Costeras Catalanas, NE de Iberia). Revista de la Sociedad Geológica de España, 21: 93-109.

Riba, O. \& Colombo, F. (2009). Barcelona: la Ciutat Vella $i$ el Poblenou. Assaig de geologia urbana. Institut d'Estudis Catalans, Barcelona: 278 pp.

Roca i Blanch, E. (2000). Montjuïc, la muntanya de la ciutat. Institut d'Estudis Catalans, Barcelona: 589 pp.

San Miguel Arribas, A. \& Masriera González, A. (1970). Contribución al estudio petrológico de los niveles de areniscas de Montjuic (Barcelona). Publicaciones del Instituto de Investigaciones Geológicas de la Diputación Provincial de Barcelona, 24: 11-34.

San Miguel de la Cámara, M. (1912). Datos para la Estratigrafía de Montjuich. Boletín de la Real Sociedad Española de Historia Natural, 12: 311-314.

Solé Sabarís, L. (1963). Ensayo de interpretación del Cuaternario barcelonés. Miscellanea Barcinonensia, 3: 7-54.

Suñer Coma, E. (1957). Resumen estratigráfico del Vindoboniense de Montjuich (Barcelona). Cursos y Conferencias del Instituto Lucas Mallada, Madrid: 49-52.

Thomas Doménech, J.M. (1953). Dos nuevos braquiuros en el Vindoboniense marino de Montjuïc. Memorias y Comunicaciones del Instituto Geológico de la Diputación Provincial de Barcelona, 6: 85-89

Thomas Doménech, J.M. (1954). Aportaciones de fauna continental en el Vindoboniense marino de Montjuich (provincia de Barcelona). Boletín de la Real Sociedad Española de Historia Natural. Sección Geológica, Tomo extraordinario homenaje a E. Hernández Pacheco, 52: 663-678.

Velasco, V., Cabello, P., Vázquez-Suñé, E., López-Blanco, M., Ramos, E., Tubau, I. (2012). A sequence stratigraphic based geological model for constraining hydrogeological modeling in the urbanizad area of the Quaternary Besòs delta (NW Mediterranean coast, Spain). Geologica Acta, 10-4: 373-393

Vicente, J. (1986). El Pliocè marí del Pla de Barcelona i del delta del Besós. Butlletí del Centre d'Estudis de la Natura de Barcelona Nord, 2: 52-60.

Villalta, J.F. (1964). Itinerario VI Montjuïc. In: Solé Sabarís, L. (ed.) Ciclo de geologia práctica sobre los alrededores de Barcelona. Colección La Nueva Geografía, Ministerio de Educación Nacional, Madrid: 99-105

Villalta, J.F. \& Rosell, J. (1965). Contribución al conocimiento de la estratigrafía de Montjuic. Revista del Instituto de Investigaciones Geológicas de la Diputación Provincial de Barcelona, 19: 83-104

Recibido el 17 de mayo de 2013 Aceptado el 19 de septiembre de 2013 